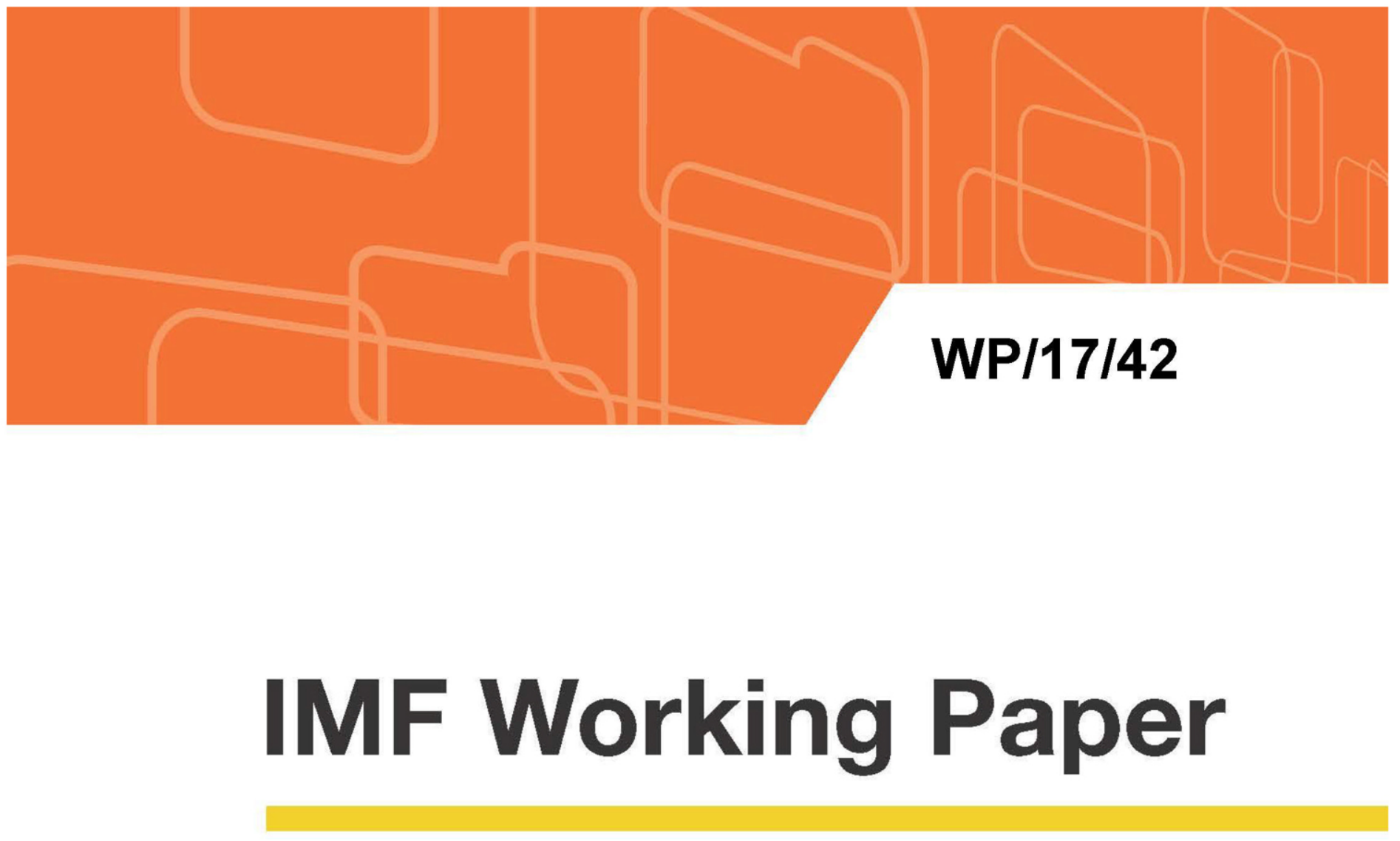

\title{
Composition of Trade in Latin America and the Caribbean
}

Xiaodan Ding and Metodij Hadzi-Vaskov

IMF Working Papers describe research in progress by the author(s) and are published to elicit comments and to encourage debate. The views expressed in IMF Working Papers are those of the author(s) and do not necessarily represent the views of the IMF, its Executive Board, or IMF management. 


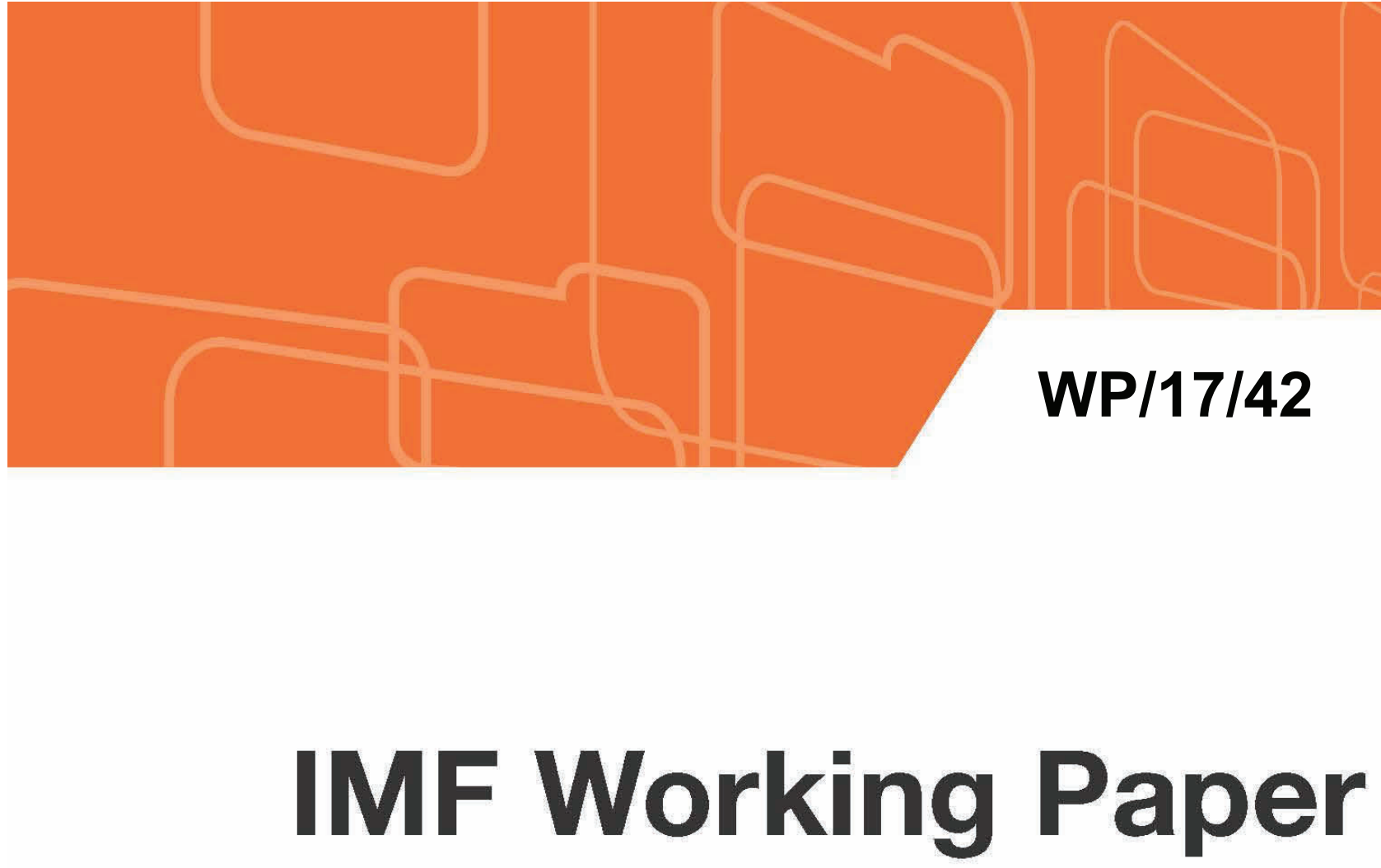

\section{Composition of Trade in Latin America and the Caribbean}

Xiaodan Ding and Metodij Hadzi-Vaskov

IMF Working Papers describe research in progress by the author(s) and are published to elicit comments and to encourage debate. The views expressed in IMF Working Papers are those of the author(s) and do not necessarily represent the views of the IMF, its Executive Board, or IMF management.

I N T E R N A T I O N A L M O N E T A R Y F F U N D 


\title{
IMF Working Paper
}

Western Hemisphere Department

\section{Composition of Trade in Latin America and the Caribbean ${ }^{1}$ \\ Prepared by Xiaodan Ding and Metodij Hadzi-Vaskov}

Authorized for distribution by Valerie Cerra

March 2017

\section{IMF Working Papers describe research in progress by the author(s) and are published to elicit comments and to encourage debate. The views expressed in IMF Working Papers are those of the author(s) and do not necessarily represent the views of the IMF, its Executive Board, or IMF management.}

\begin{abstract}
This study analyzes composition of goods trade in Latin America and the Caribbean (LAC) along four main dimensions: revealed comparative advantage, product complexity, sophistication, and diversification. After describing some key trade patterns over the last half century, it compares the findings for LAC with other regions. Second, the study investigates how infrastructure quality, education, and tariff levels affect export composition. Third, using an approach based on product proximity, it aims to predict changes in LAC's future composition of exports. The study concludes that policies to upgrade human capital and infrastructure are essential for increasing LAC's export share in high-skill products.
\end{abstract}

JEL Classification Numbers: F10, F14, O33

Keywords: Trade, Export Composition, Economic Complexity, Diversification, Comparative Advantage, Latin America, Caribbean

Author's E-Mail Address: XDing@imf.og; MHadziVaskov@,imf.org

\footnotetext{
${ }^{1}$ The authors are grateful to Valerie Cerra for overall guidance and continued support, participants at the WHD Seminar for useful comments and suggestions, and Steve Brito for help with data issues. This paper was prepared as a background study for the Western Hemisphere Department's Cluster Report on Trade Integration in Latin America and the Caribbean.
} 


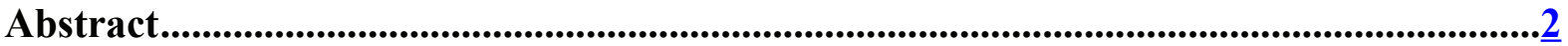

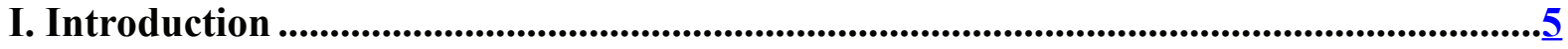

II. Dimensions of Trade Composition .................................................................................................6

III. Dataset and Data Description......................................................................................................

IV. Trends in Trade Composition ........................................................................................11

A. Revealed Comparative Advantage ........................................................... 11

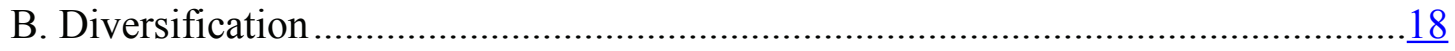

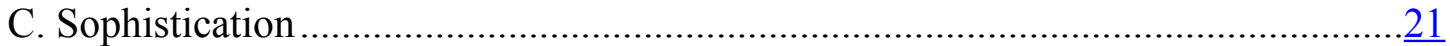

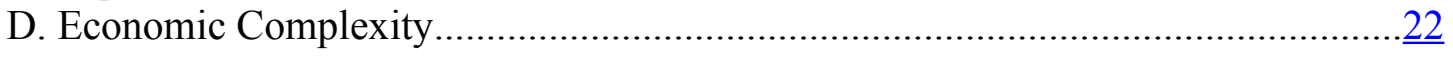

V. Product Proximity and Predicting Future Composition of Trade ...............................24

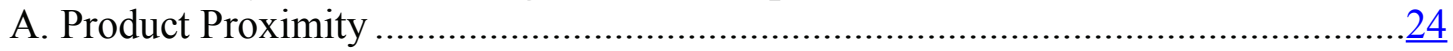

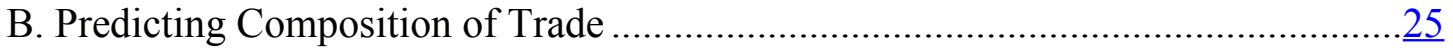

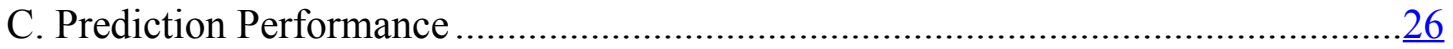

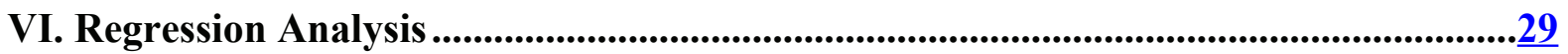

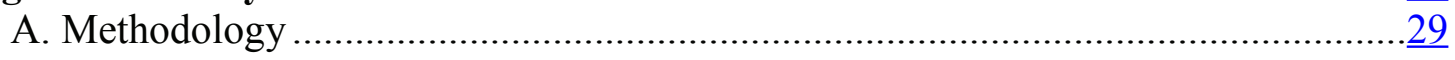

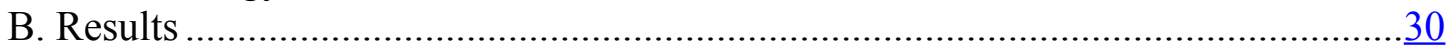

VII. Impact of Trade Agreements ...............................................................................

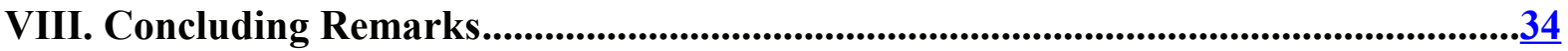

IX. References ...........................................................................................................................................

\section{Tables}

1: Determinants of the Composition of Trade ............................................................. $\frac{31}{31}$

2: Determinants of the Composition of Trade: IV Regressions ......................................... $\frac{31}{33}$

3: Regression Results: Impact of Trade Agreements on Export Composition .........................

\section{Figures}

1: Revealed Comparative Advantage for Latin America and the Caribbean.........................12

2: Revealed Comparative Advantage for LA6 ......................................................... 12

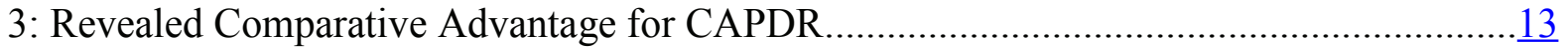

4: Revealed Comparative Advantage for the Caribbean...................................................14

5: Revealed Comparative Advantage for Different Regions ............................................ 15

6: Revealed Comparative Advantage in Different Product Categories ................................ $\frac{17}{18}$

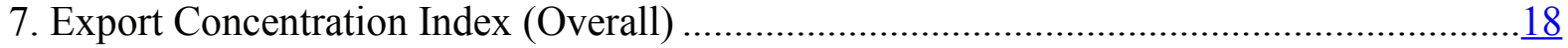

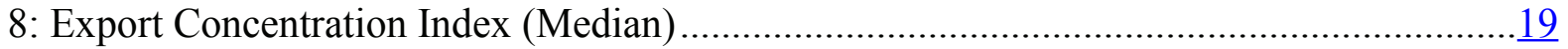

9: Export Concentration Index (by Country) ..............................................................

10: Export Concentration Index for the Caribbean .................................................... 20

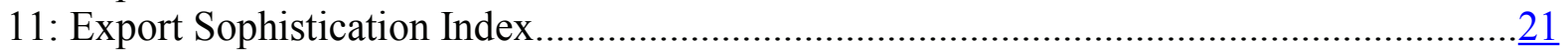




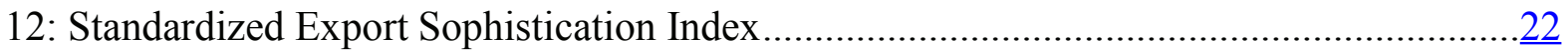

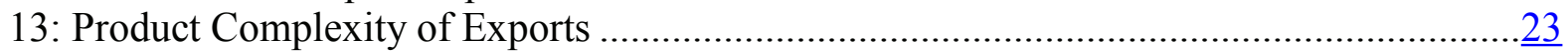

14: Actual and Predicted Areas of Comparative Advantage ..................................................26

15: Performance of Predictions for Comparative Advantage ..................................................27

16: Actual and Predicted Areas of Comparative Advantage (Dynamic) ………………..........28

17: Performance of Predictions for Comparative Advantage (Dynamic)..................................28

18: Event Studies: Impact of Trade Agreements on Export Composition.................................33

\section{Boxes}

1: Skill and Technology-Intensity Product Classification from UNCTAD ..............................10

2. Standard International Trade Classification (SITC) ........................................................10

\section{Appendices}

I. Country Groupings .$\underline{38}$

II. Distribution of Product Complexity Allowing Movements Across Quintiles

III. Robustness of Predictions for RCAs Across Product Groups to Alternative Time

Horizons.

IV. Additional Regression Results..............................................................................41

V. Panel Vector Autoregressive Model ...........................................................................42 


\section{INTRODUCTION}

Economic performance is not only influenced by how much countries trade, but also by what kind of goods they actually trade. For instance, some goods contain higher technological content and allow faster technology transfer through interactions with trading partners, while others are basic commodities that offer limited prospects for learning new skills. Some products can be exported by many countries in the world, while others are exported by a few producers only, and thereby, offer an opportunity to capture higher returns. In general, certain types of products are likely to be more desirable, given that the type of exports in which a country specializes seems to have important implications for subsequent economic performance. ${ }^{2}$ While the countries' endowments of factors of production, such as physical capital, labor, and natural resources, have typically been emphasized as important determinants of the pattern of specialization and exports, additional elements, such as increasing returns to scale, network effects, technological spillovers or institutional quality are found to play a role in trade patterns as well. ${ }^{3}$

In this context, an analysis of the composition of trade may be particularly relevant for the region of Latin America and the Caribbean (LAC), given the specific factors that have shaped its economic and trade history. For instance, natural resources and commodities have traditionally represented a significant share of total exports for many countries in LAC, which may have contributed to limiting resources needed for further development of other segments of the economy. Moreover, the region has passed through different initiatives for industrialization, including through import-substitution policies, which isolated certain industries from external competition, but also limited channels for technology transfer.

In which products does LAC enjoy comparative advantage? How have its comparative advantages evolved over time and how have they reflected structural changes in the domestic economies and the global market? Has LAC's export portfolio become more sophisticated and complex over time? What factors played a role in the evolution of these trends and patterns? What are the areas in which LAC is more likely to gain comparative advantage in the future? These are some of the issues this study aims to shed light on. Doing so, it takes stock of several important patterns and trends in LAC's export portfolios over half a century (1962-2013) and investigates the importance of different policy-related factors in shaping LAC's composition of trade. Given the limitations to collect data of comparable quality and sufficient detail, this study does not cover trade in services and focuses on gross trade flows rather than value-added trade flows.

\footnotetext{
${ }^{2}$ For example, see Hausmann, Hwang, and Rodrik (2007) and Hausmann et al. (2014).

${ }^{3}$ See, for instance, Krugman (1979) on role of increasing returns and monopolistic competition, Banerjee and Munshi (2004) on networks, and Levchenko (2007) on institutional quality.
} 
The rest of the paper is organized as follows. Section 2 provides an overview of several key concepts related to composition of trade, and Section 3 describes the dataset used in our analysis. Section 4 documents the evolution of LAC's export composition and Section 5 provides a simple approach for predicting the composition of trade based on the current export basket. Section 6 presents regression results on the determinants of trade composition, and Section 7 includes event studies on the impact of trade agreements in LAC. Section 8 summarizes the main findings and their policy relevance, and provides some concluding remarks.

\section{Dimensions of Trade Composition}

The composition of a country's exports can be described from various perspectives. For example, one may analyze the composition on the basis of product characteristics, such as quality, technological content, processing stage, or final use, while others will concentrate on the level of diversification across different product categories or the differences in the network of trading partners. Our analysis of trade composition proceeds along four key dimensions: revealed comparative advantage (RCA), diversification across product categories, product sophistication, and economic complexity. Before we embark on our analysis, in this section we provide definitions and brief descriptions of each of these concepts.

Revealed comparative advantage (RCA) shows the relative advantage or disadvantage that a country has in exporting a certain good or group of products. It is measured here according to the RCA index introduced by Balassa (1965) that compares the share of a certain good in a country's total exports with the share of that product's world exports in total world exports of all goods. In this way, RCA larger than one indicates that a country exports more than its "fair" share of certain product, and therefore, enjoys revealed comparative advantage in that product. Similarly, RCA below unity means that a country exports less than its "fair" share in world trade, and therefore, has a revealed comparative disadvantage for certain product.

The RCA index for country $j$ in good $i$ is calculated with the following formula:

$$
R C A_{i}^{j}=\frac{\frac{x_{i}^{j}}{\sum_{i} x_{i}^{j}}}{\frac{\sum_{j} x_{i}^{j}}{\sum_{i} \sum_{j} x_{i}^{j}}}
$$

Where $x_{i}^{j}$ stands for gross exports of product $i$ for country $j$, so the numerator $x_{i}^{j} / \sum_{i} x_{i}^{j}$ refers to the share of product $i$ in the overall exports of country $j$, and the denominator $\sum_{j} x_{i}^{j} / \sum_{i} \sum_{j} x_{i}^{j}$ captures the global share of product $i$ exports in total world exports. Hence, if exports of product $i$ for country $j$ represents 5 percent of its total exports, while global exports of product $i$ represent only $2 \frac{1}{2}$ percent of total world exports, then country $j$ is said to enjoy RCA of 2 in product $i$. 
Diversification is a multifaceted concept that can be defined in different ways. Here we measure product diversification (concentration) with the Herfindahl concentration index given by the following formula:

$$
H I_{j t}=\sum_{s}\left(\frac{x_{s j t}}{\sum_{s} x_{s j t}}\right)^{2}
$$

Where $x_{s j t}$ represents exports of product category $s$ for country $j$ at time $t$. This concentration index is calculated across 10 product categories in accordance with the Standard International Trade Classification (SITC) for each country in the dataset. Higher HI index values indicate less product diversification across groups of products differentiated on the basis of the products' economic function.

Sophistication of a product aims to capture the potential income level a product may control based on the income levels of countries that export that product. For instance, if a country starts exporting a (relatively low-end version of) new product that is exported by relatively rich countries, it may mean that over time this country can increase the prices charged and increase its income. In measuring product sophistication, we follow Hausmann, Hwang, and Rodrik (2007) by computing the productivity level PRODY $Y_{i t}$ associated with product $i$ at time $t$ as the weighted average of per capita GDP levels of countries exporting that product, with the weights corresponding to the revealed comparative advantage of each country in that product: ${ }^{4}$

$$
P R O D Y_{i t}=\sum_{j}\left[\frac{\left(\frac{x_{i j t}}{\sum_{i} x_{i j t}}\right)}{\sum_{j}\left(\frac{x_{i j t}}{\sum_{i} x_{i j t}}\right)} G D P p c_{j t}\right]
$$

Similarly, the sophistication level that is associated with the export portfolio of country $j$ at time $t$ is calculated as the weighted average of productivity levels (PRODYs) for all products this country exports, with the weights corresponding to the shares of these products in total exports of country $j$ :

$$
E X P Y_{j t}=\sum_{i}\left(\frac{x_{i j t}}{\sum_{i} x_{i j t}}\right) P R O D Y_{i t}
$$

While these measures of product and export portfolio sophistication have been widely used in the literature, they necessarily imply an increasing trend of sophistication over time given that GDP per capita for most countries persistently follows an upward trend. Therefore, to account for this time trend, we also calculate product productivity $P R O D Y_{i t}^{S}$ by replacing GDP per capita for country $j$ in the original formula with GDP per capita for country $j$ relative to the corresponding value for the world:

\footnotetext{
${ }^{4}$ Hausmann, Hwang, and Rodrik (2007) argue that the rationale for using revealed comparative advantage as a weight in the formula is to ensure that country size does not distort the ranking of products. The use of RCA allows higher weights for those countries that export more than their fair share in certain product.
} 


$$
P R O D Y_{i t}^{S}=\sum_{j}\left[\frac{\left(\frac{x_{i j t}}{\sum_{i} x_{i j t}}\right)}{\sum_{j}\left(\frac{x_{i j t}}{\sum_{i} x_{i j t}}\right)} \frac{G D P p c_{j t}}{G D P c_{j t}^{\text {world }}}\right]
$$

and recalculate a standardized measure for sophistication for country $j$ 's export basket accordingly:

$$
E X P Y_{j t}^{s}=\sum_{i}\left(\frac{x_{i j t}}{\sum_{i} x_{i j t}}\right) P R O D Y_{i t}^{s}
$$

Economic Complexity. The concept of economic complexity is related to the amount of productive knowledge that is embedded in a country's products. ${ }^{5}$ Some products require a lot of capabilities and knowledge and can be produced only by a limited group of countries. In this respect, countries that have more capabilities and knowledge are typically able to produce a more diversified set goods. Moreover, these countries are also able to produce goods that only a selected group of a few other countries can produce. In turn, a country's ability to both produce many goods and produce a very distinguished set of goods suggests that the country is likely to possess complex knowledge and skills that only a few, if any, other countries can mimic or replicate.

Hence, higher complexity is linked to lower ubiquity (products that demand large volumes of knowledge that are feasible in a few locations only) and higher diversity (more knowledge can produce a more diverse set of products). A calculation of economic complexity, therefore, needs to correct the information that ubiquity and diversity convey by using each one to correct for the other (Hausmann et al. 2014). In this context, product complexity will be calculated by the average diversity of countries that produce/export that product, corrected for the average ubiquity of the products in these countries' portfolio and so forth. Similarly, economic complexity of a country will be measured by the average ubiquity of products that the country produces (exports), corrected for the average diversity of the products that make those products, etc. This recursive process of average ubiquity and average diversity provides a measure for the Product Complexity Index (PCI) and countries' Economic Complexity Index (ECI). ${ }^{6}$

\section{Dataset AND DAta Description}

Data used in this analysis comes from several sources. The core part of the dataset employed in the calculation of dimensions of trade composition consists of series on gross exports of goods that come from the United Nations Commodity Trade Statistics (UN COMTRADE) database. We match disaggregated product-level series at the 4-digit

\footnotetext{
${ }^{5}$ For instance, see Hidalgo and Hausmann (2009) and Hausmann et al., (2014).

${ }^{6}$ For a formal derivation of Product Complexity Index (PCI) and the Economic Complexity Index (ECI), see Hausmann et al. (2014) and the Observatory of Economic Complexity resources.
} 
according to the SITC classification. ${ }^{7}$ The dataset covers gross exports for 240 countries and territories in 997 different products at annual frequency over the period 1962-2013. ${ }^{8}$ Standard macroeconomic data series, such as GDP and GDP per capita, come from the World Economic Outlook (WEO) database. We group countries into different regions in line with the WEO country classification and separate countries of LAC into sub-regions (Appendix I provides description of country classification across regions).

In our formal analysis we explore the effect of several factors on the composition of trade. For instance, we include secondary school enrollment rate and the percentage of tertiary enrollment from the World Development Indicators (WDI) database as indicators for countries' education levels. Quality of infrastructure is measured by rail density (rail lines per square kilometer of land area), and fixed telephone subscriptions (per 100 inhabitants) from the WDI database as well as the infrastructure quality scores from the World Economic Forum (WEF) database. Income inequality is measured by the Gini index series from the Standardized World Income Inequality Database (SWIID). Tariff data series are retrieved from the World Bank's World Integrated Trade Solution (WITS).

\section{We follow two product classifications in order to focus on some essential aspects of} trade composition. Namely, we use the skill- and technology-intensity product classification from UNCTAD for most of our analysis (Box 1). Besides distinguishing between technology-intensive and other products, it also allows differentiation within technologyintensive products according to the level of technology required for their production. In addition, this classification allows a differentiation between mineral fuels and non-fuel primary commodities, which may be relevant for many countries in LAC that are highly dependent on one type of commodities, but not the other. When looking at export product diversification (concentration), we categorize products on the basis of their economic function and processing stage according to the main sections of the SITC classification (Box 2).

\footnotetext{
${ }^{7}$ We use the conversion and correspondence tables from the United Nations Statistics Division for matching product level data series.

${ }^{8}$ The dataset contains series for different territories and former countries that do not exist anymore.
} 
Box 1: Skill and Technology-Intensity Product Classification from UNCTAD

This classification distinguished products according to their level of skill- and technologyintensity. It has been developed by Basu and Das (2011) and Basu (forthcoming) on the basis of UNCTAD $(1996,2002)$ and Lall $(2000)$. According to this classification, we organize in the following seven categories:

- High skill- and technology intensive manufactures

- $\quad$ Medium skill- and technology intensive manufactures

- $\quad$ Low skill- and technology intensive manufactures

- $\quad$ Resource-intensive manufactures

- $\quad$ Non-fuel primary commodities

- Mineral fuels

- Unclassified products

\section{Box 2. Standard International Trade Classification (SITC)}

Classification that takes account of products' economic function. Developed by the United Nations with the purpose to classify trade products not only on the basis of their material/physical properties, but also according to their economic function and the processing stage, the SITC into the following ten broad sections:

- $\quad$ Food and live animals

- Beverages and tobacco

- $\quad$ Crude materials, inedible, except fuels

- $\quad$ Mineral fuels, lubricants and related materials

- $\quad$ Animal and vegetable oils, fats, and waxes

- Chemicals and related products

- $\quad$ Manufactured goods (classified by material)

- $\quad$ Machinery and transport equipment

- $\quad$ Miscellaneous manufactured articles

- $\quad$ Commodities not classified elsewhere

Finally, we include data on economic complexity obtained from the Observatory of Economic Complexity (atlas.media.mit.edu). We make use of two data series: the product complexity index (PCI) and the country-level economic complexity index (ECI). 


\section{Trends In Trade Composition}

This section takes stock of the evolution in LAC's composition of goods trade over half a century. It presents the main trends of RCA, product diversification, sophistication, and economic complexity for the overall region, distinguishes between sub-groups of countries within the region, and provides a comparison with other regions in the world.

\section{A. Revealed Comparative Advantage}

Using the dataset described earlier we calculate RCAs for all countries and regions over the period 1962-2013. We group export products into the seven categories explained in Box 1 according to their skill- and technology-intensity. We follow the WEO country classification in categorizing countries across different regions. When calculating regionwide RCAs, we use sums of gross exports for all countries that belong to that region, so that bigger exporters also have larger weights in the RCA calculations.

LAC region has consistently maintained a RCA in mineral fuels and non-fuel primary commodities over the past half a century. Results presented in Figure 1 suggest that LAC's RCA in non-fuel primary commodities has been rather stable and constantly above one over the last several decades, reflecting the importance of different metals, ores, foodstuffs, and other commodities in the region's overall export basket. Similar, the region enjoyed a stable RCA above one in mineral fuels over the last three decades, which was preceded by a period of declining RCA in the 1960s and 1970s, largely reflecting the decline in Venezuela's oil production.

On the other hand, the LAC region did not manage to consistently establish RCA (above one) in any other product group. For instance, the most promising development was the steady increase in resource-intensive manufactures since the 1980s that resulted in RCA above one from the mid-1990s till the mid-2000s. However, this trends seems to have reversed since then, in parallel with the trend increase in LAC's RCA in primary commodities. In addition, LAC as a region never managed to establish RCA in skill- and technology-intensive manufactures.

The LA6 sub-group of countries accounts for most exports in LAC. ${ }^{9}$ Hence, it is not surprising that RCAs for LA6 in Figure 2 follow a very similar pattern as RCAs for the overall LAC region in Figure 1. In fact, the only major difference is the absence of a sharp decline in RCA for mineral fuels in the 1960s and 1970s, which reflects the fact that Venezuela, which experienced a sharp decline in oil production over this period, is not included in the LA6. On the other hand, the boom in Mexico's oil production in the late

\footnotetext{
${ }^{9}$ LA6 refers to Brazil, Chile, Colombia, Mexico, Peru, and Uruguay.
} 
1970s and early 1980s is clearly captured by the sharp increase in LA6's comparative advantage in mineral fuels. ${ }^{10}$
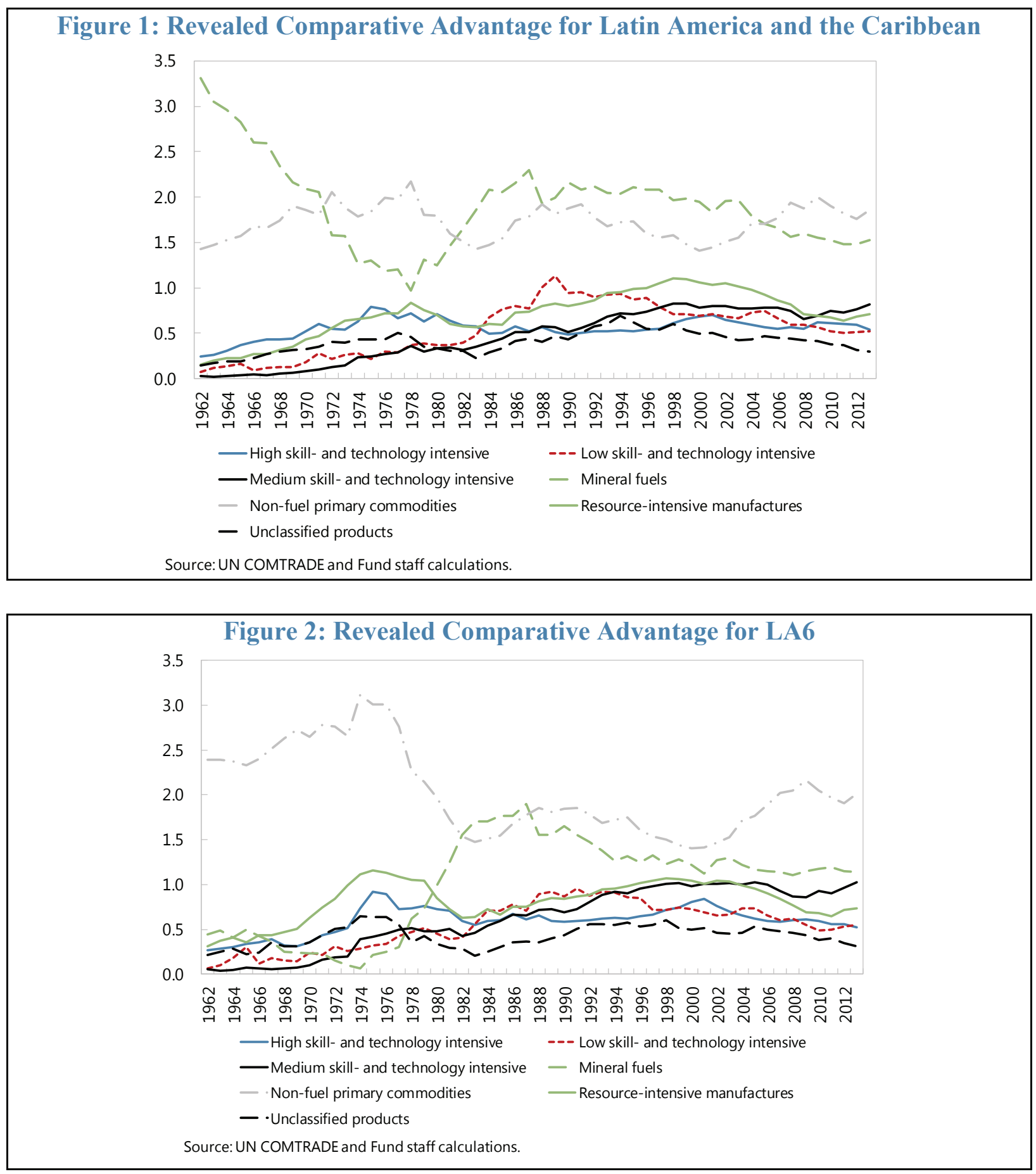

${ }^{10}$ Mexico's oil boom refers to the period 1977-1981 when the state-owned oil company PEMEX roughly doubled its oil production. 


\section{The evolution of RCAs in different product groups for the countries of CAPDR differs} significantly from that of LA6 and overall LAC. ${ }^{11}$ In contrast to LA6, this sub-group never enjoyed comparative advantage in mineral fuels, and its high RCA in non-fuel primary commodities sharply declined since the mid-1980s (Figure 3). The latter finding likely reflects the gradual decline in relative importance of agricultural commodities, fruits, and vegetables in these countries' export baskets over the last three decades. In addition, CAPDR shows a high RCA in resource-intensive manufactures since the mid-1980s and a surge in low skill- and technology-intensive manufactures in the $1980 \mathrm{~s} .{ }^{12}$ These developments likely capture the increasing importance of the maquila sector located in special economic zones of the CAPDR countries since the 1980s, which has been especially focused on low-skill and resource-intensive manufactures, such as textiles, footwear, tobacco, simple components and devices, and others. ${ }^{13}$

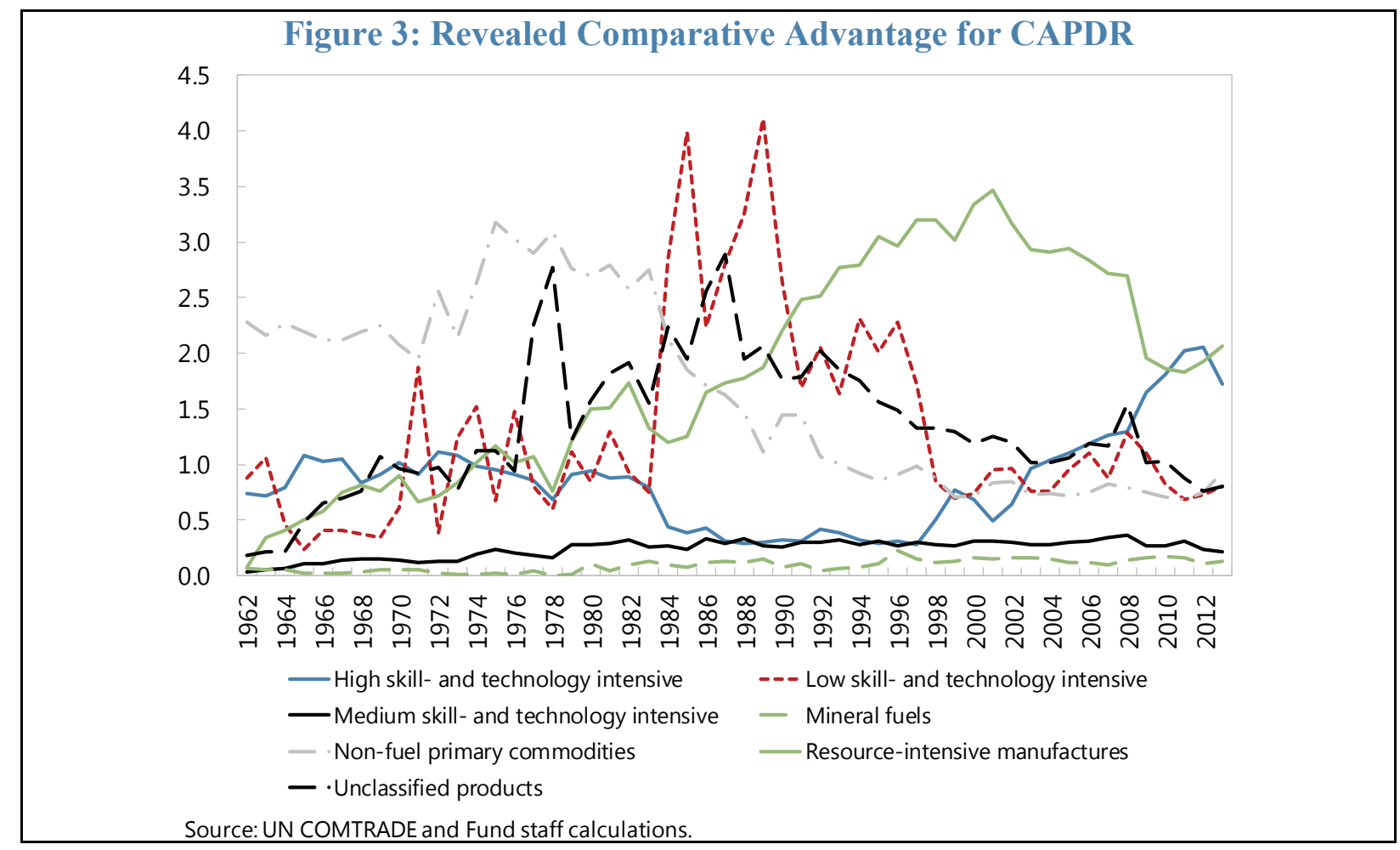

${ }^{11}$ CAPDR includes Costa Rica, Dominican Republic, El Salvador, Guatemala, Honduras, Nicaragua, and Panama. List of country groupings is provided in Appendix I.

12 The high variability in the results for RCA in low-skill and technology-intensive manufactures likely reflects the data limitations and possible mismeasurements.

13 The maquila sector refers to factories that generally import (raw) materials duty-free under special legal arrangements, assemble or process the imported materials, and export the assembled or manufactured products abroad, sometimes back to the destination of origin of the raw materials. 
While services remain the main trade component for the Caribbean, the pattern of goods trade can provide an insight about evolution of RCAs for this region as well.

Figure 4 indicates that the group of Caribbean economies steadily lost its RCA in mineral fuels and high skill-intensive products, while they gained RCA in non-fuel primary commodities and low skill- and technology-intensive manufactures.

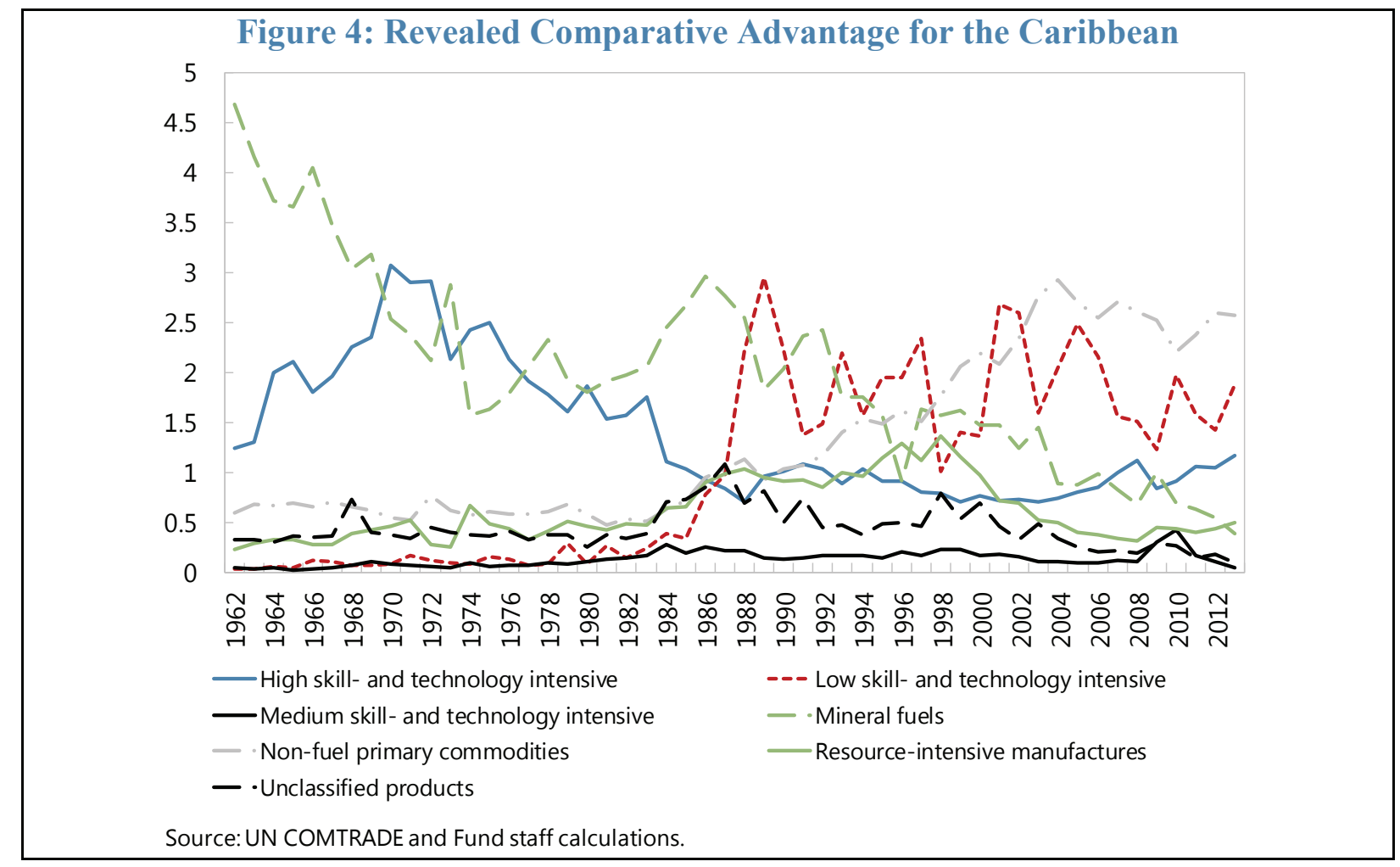

Compared to other regions in the world, LAC has a more limited number of product categories with comparative advantage (Figure 5). LAC has RCA above one in only two categories, while advanced economies have it in 4-5 categories, Emerging Asia in 3-4 categories, Emerging Europe in 3. Only MENA's RCA is more limited, as this region consistently shows a very high RCA in a single category (mineral fuels). ${ }^{14}$ In addition, Advanced economies, Emerging Europe and Emerging Asia have comparative advantage in categories that comprise of more skill- and technology-intensive products.

\footnotetext{
${ }^{14}$ While MENA has improved its RCA in non-fuel primary commodities over the last decade, the RCA still does not surpass the value of one.
} 
Figure 5: Revealed Comparative Advantage for Different Regions

Latin America and the Caribbean

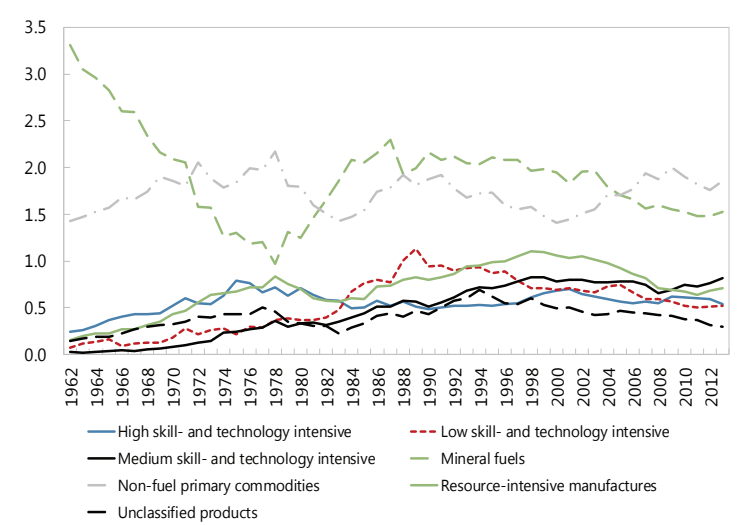

Source: UN COMTRADE and Fund staff calculations.

\section{Emerging Europe}

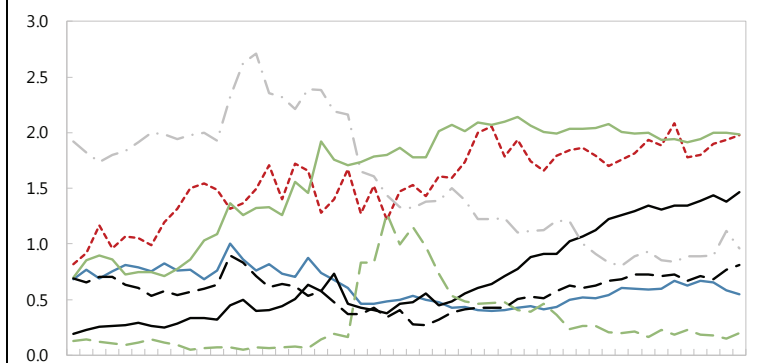

0.0

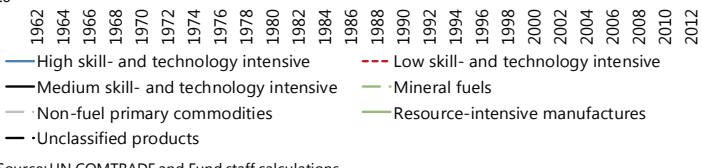

Source: UN COMTRADE and Fund staff calculations.

\section{Middle-East and North Africa}

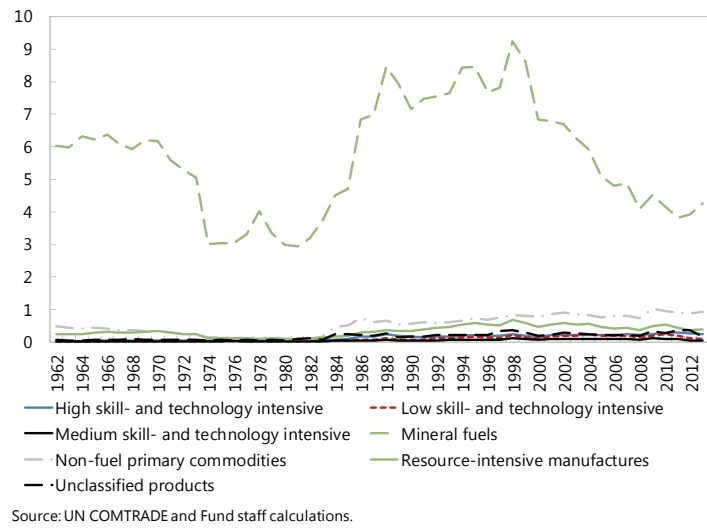

Advanced economies

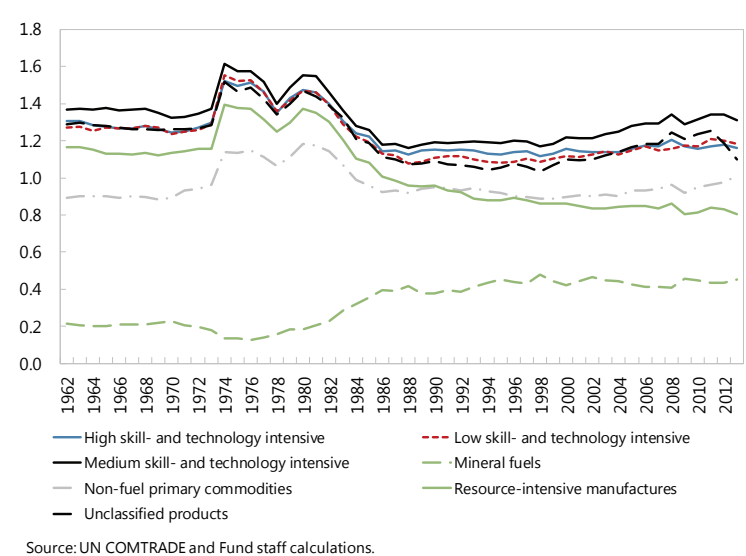

Emerging Asia

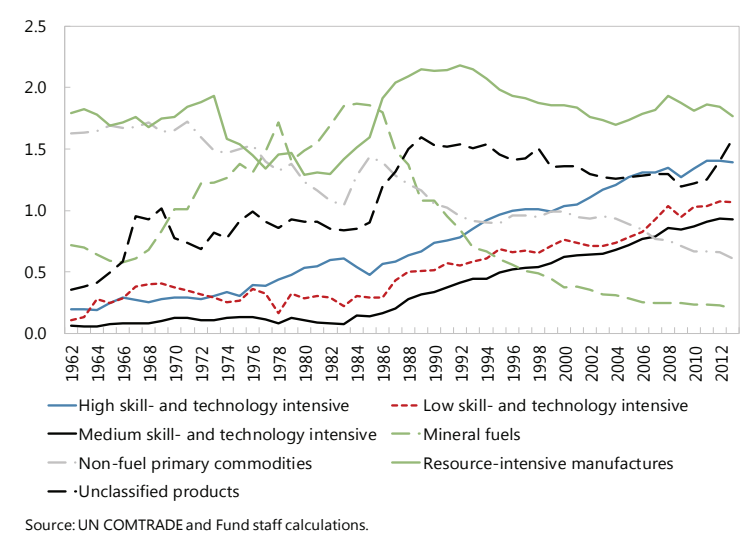

Sub-Sahara Africa

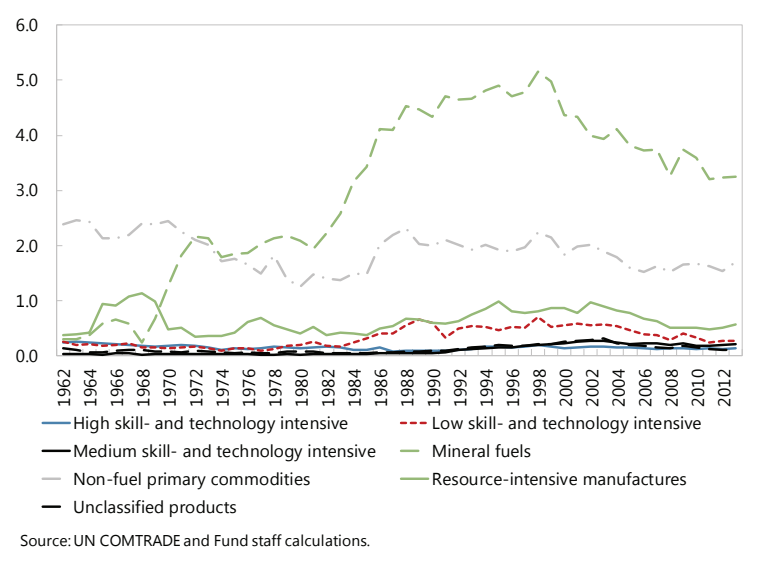

\section{CInternational Monetary Fund. Not for Redistribution}


RCAs for different product categories evolved differently across regions. Figure 6 shows the evolution of regions' RCAs for different product categories and conveys several important messages. For instance, LAC's RCA in high-skill manufactures stagnated over the past decades and the region never managed to obtain RCA above the value of one. This stands in contrast to Emerging Asia, a region that had lower RCA than LAC till the mid1980s, but followed a trend of substantial and continued improvement over the entire period, which resulted in surpassing the advanced economies' RCA in high-skilled products in the last decade.

\section{LAC lowered its RCA shortfall in medium-skill products, continually increasing its RCA from the early 1970s till the late 1990s, largely reflecting the process of} industrialization in many economies in the region. While LAC's trend was quite similar to Emerging Europe and Emerging Asia till the late 1990s, LAC's RCA in medium-skill manufactures stagnated in the $2000 \mathrm{~s}$, likely as a result of the region's refocus on commodities in this period. In contrast, the other emerging regions continued to improve their RCAs, and Emerging Europe even overtook the advanced economies group lately, which comes as a consequence of the Emerging Europe's higher integration with Europe's advanced economies, including through the participation in global production and supply chains..$^{15}$

\section{LAC improved its comparative advantage in low skill and technology-intensive manufactures, particularly in the 1980s. This development is likely related to the} expansion of the maquila sector in various countries in the region, but then moved on a declining path since the 1990s. ${ }^{16}$ Emerging Asia also lowered its RCA shortfall in low skill and technology-intensive manufactures, and surpassed LAC in the mid-2000s with an RCA value of about one. Nonetheless, Emerging Europe has consistently maintained the highest RCA in this category.

RCA in resource-intensive manufactures improved somewhat for LAC in the 1980s and 1990s, briefly crossing the value of one in 1998-1999. ${ }^{17}$ However, it moved on a downward trend in the 2000s, roughly coinciding with the increase in relative importance of the primary commodities sector. Emerging Europe and Asia remain the only regions with comparative advantage that is consistently above one over the last few decades. The evolution of RCAs in the two commodity-based categories shows that LAC further strengthened its RCA in nonfuel primary commodities during the latest commodity boom in

\footnotetext{
15 The automotive sector is one of the most important industries in this product category, and Emerging Europe's increasing integration in the automobile industry's supply chains is an important factor that contributed to the strong increase in its RCA.

${ }^{16}$ The jump in the mid-1980s is particularly pronounced in the CAPDR countries, which also experienced a significant expansion of the maquila sector in this period.

${ }^{17}$ A large part of this increase in RCA is explained by the expansion of resource-intensive manufactures in the CAPDR sub-region.
} 
the 2000s and surpassed Sub-Saharan Africa to reach the highest RCA among major world regions. This implies that the share of non-fuel commodities in total exports increased more for LAC than for the world as a whole. However, LAC's RCA in mineral fuels decreased over this period that was marked by a strong increase in oil prices, which mainly reflects the reduction in Venezuela's oil production. ${ }^{18}$

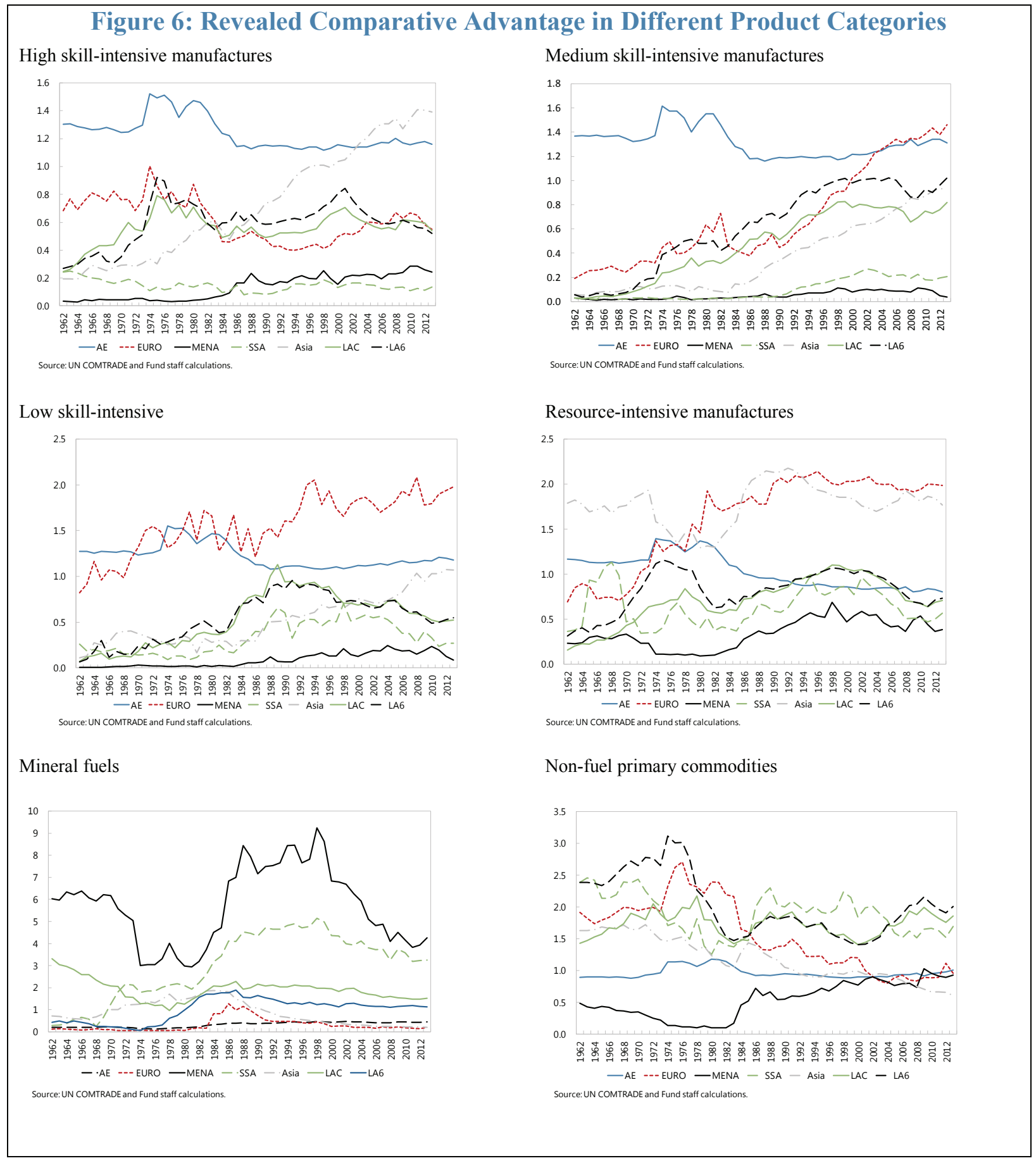

${ }^{18}$ The advanced economies constitute the only major group that increased its RCA in mineral fuels in the 2000s. 


\section{B. Diversification}

The Herfindahl concentration index suggests that the overall export portfolio of the countries in LAC has been one of the most diversified among major country groups. In fact, the overall export concentration index has declined since the mid-1980s, implying that LAC is the region with the highest level of diversification across product categories defined on the basis of the products' economic function and processing stage. Figure 7 also shows that differences exist among country sub-groups within LAC, as the group of relatively smaller economies in CAPDR shows higher levels of product concentration compared to the LA6 economies.

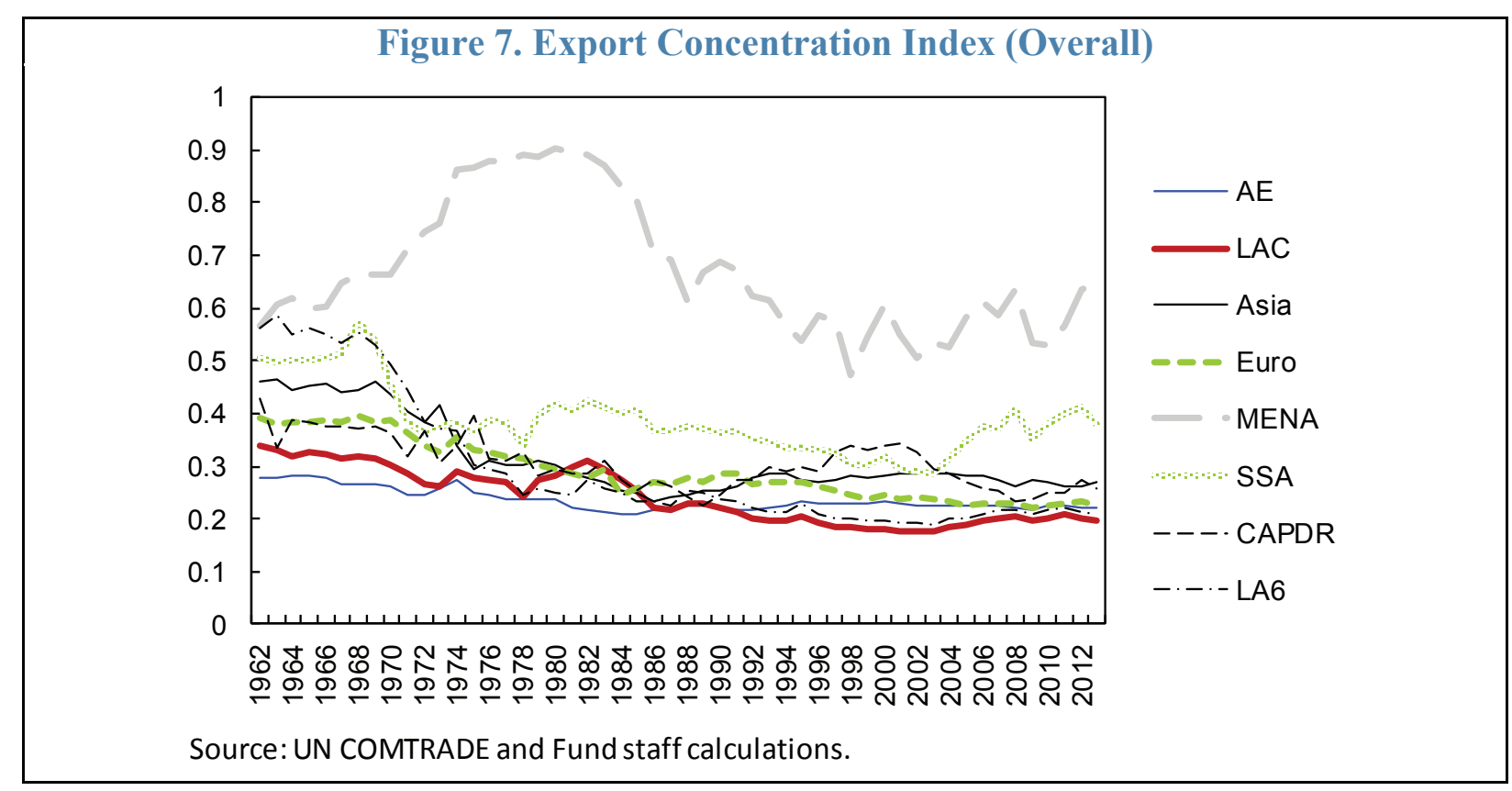

Nonetheless, markedly different conclusions emerge when we measure diversification by the median value of the concentration index for countries in the region. Figure 8 presents such calculations instead of the concentration index calculated for the region's overall export portfolio. For instance, LAC seems markedly less diversified than the groups of advanced economies and Emerging Europe, though still remains more diversified compared to MENA, Emerging Asia, and Sub-Saharan Africa. Moreover, the findings based on the median concentration index in Figure 8 imply that there are large differences across countries within LAC. 
Figure 8: Export Concentration Index (Median)

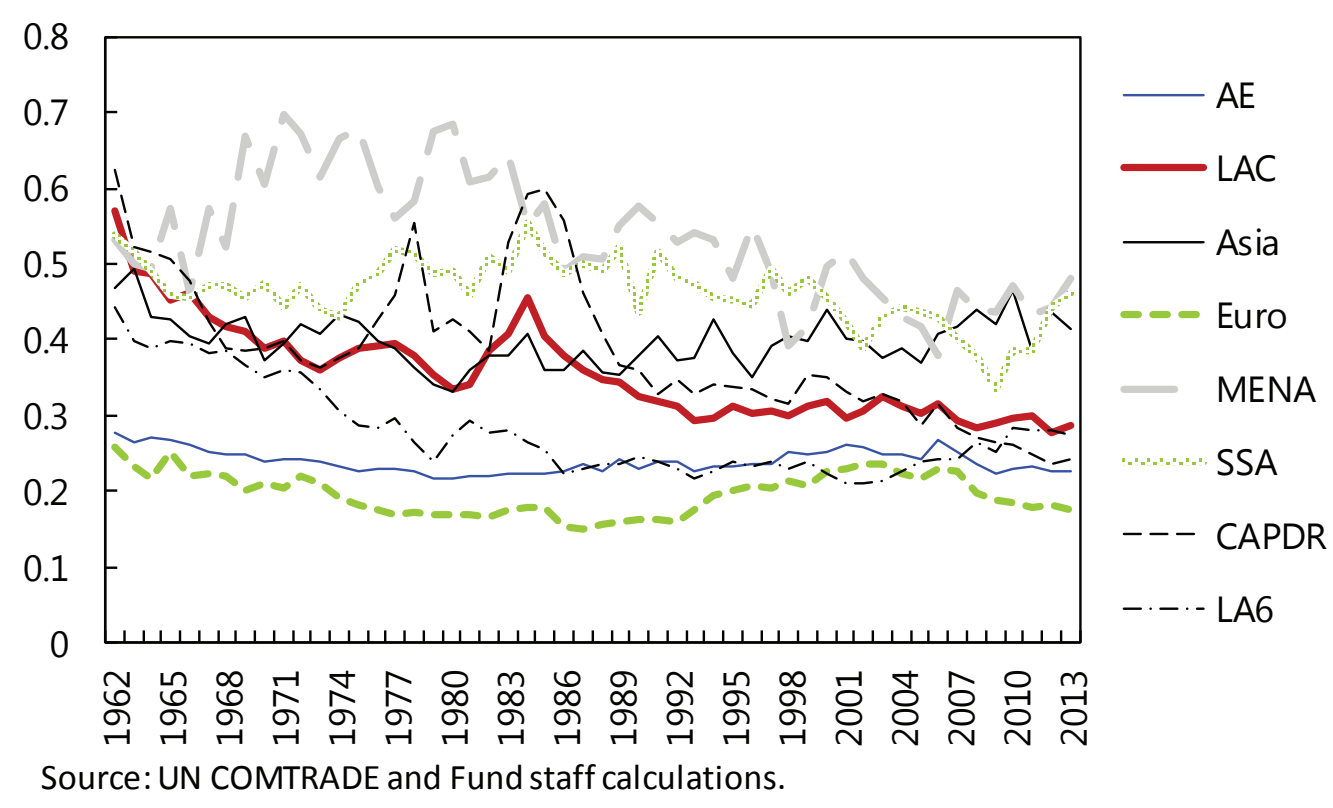

Diversification in LAC has been mainly driven by the largest economies. A closer look at the country sub-groups (Figure 7) and the country-specific export concentration indices (Figure 9) suggests that the overall concentration (diversification) in LAC is mainly driven by the LA6, particularly the two largest economies Brazil and Mexico. Both of them show low levels of export concentration, and they seem to have compensated each other, as the increase in Mexico's concentration in the 1980s was largely offset by the declining concentration in Brazil's export portfolio.

There are also large differences in the level of export concentration among the countries in the Caribbean (Figure 10). In addition, the Caribbean countries generally have higher export concentration than LAC and countries in Latin America, with the exception of Venezuela. There does not seem to emerge a general diversification trend among the Caribbean economies: while some of them managed to lower the concentration of their export portfolios, others actually increased their export concentration. Nevertheless, it is worth noting that the findings presented in Figure 10 only refer to trade in goods, which is less important to trade in services for many economies in the Caribbean. 

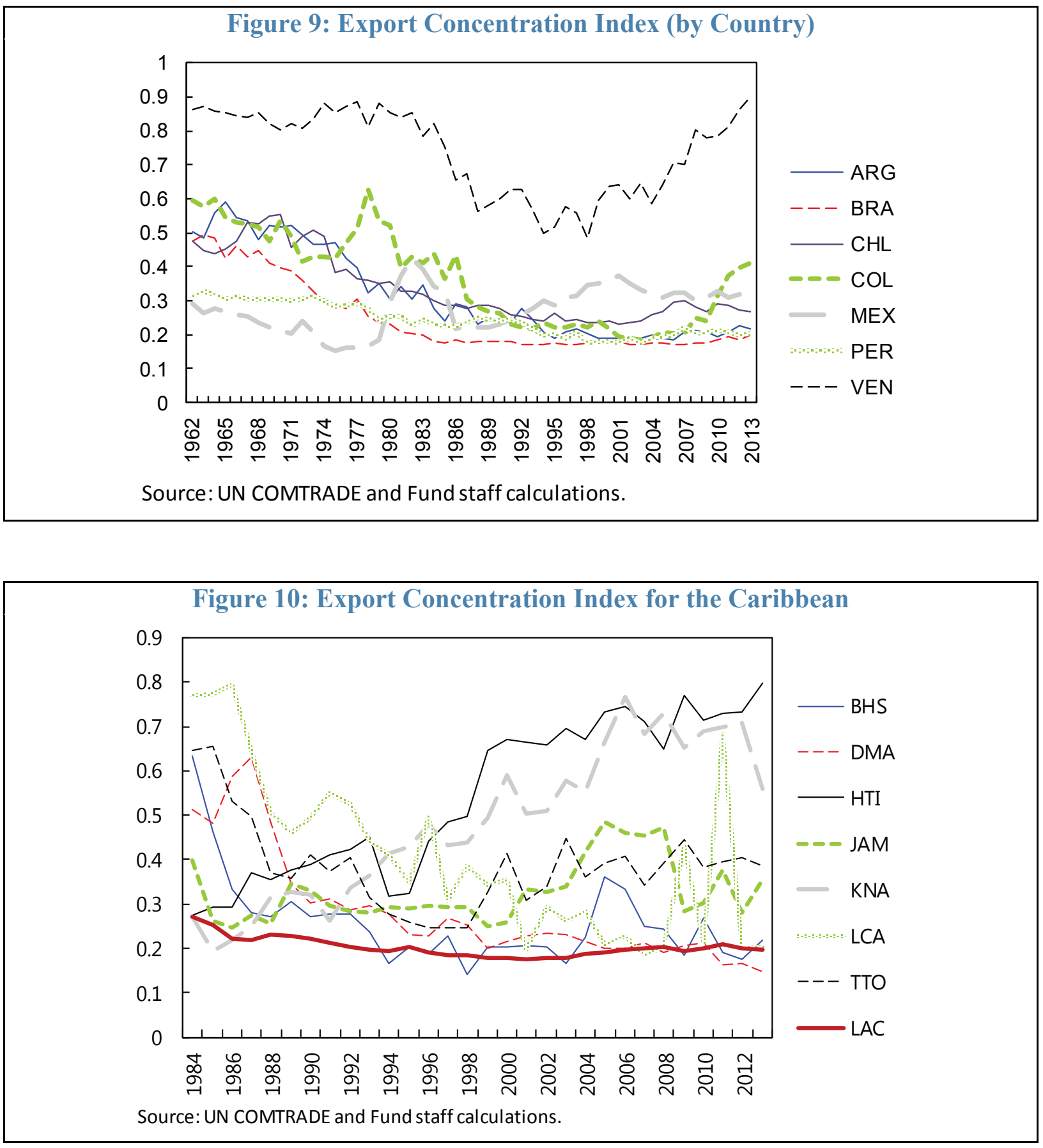


\section{Sophistication}

Export sophistication, as a measure of the export baskets' potential income level, has improved for all major regions over the last decades. The LAC region had a similar level of export sophistication in the 1960s as most other regions of emerging and developing countries (somewhat lower than Emerging Europe). LAC surpassed MENA and Sub-Saharan Africa since the 1970s and managed to maintain the difference in terms of export sophistication, but performed worse than Emerging Asia, particularly since the 1990s. In addition, the advanced economies and Emerging Europe have consistently exported products with higher average sophistication level than LAC over the last half a century ${ }^{19}$.

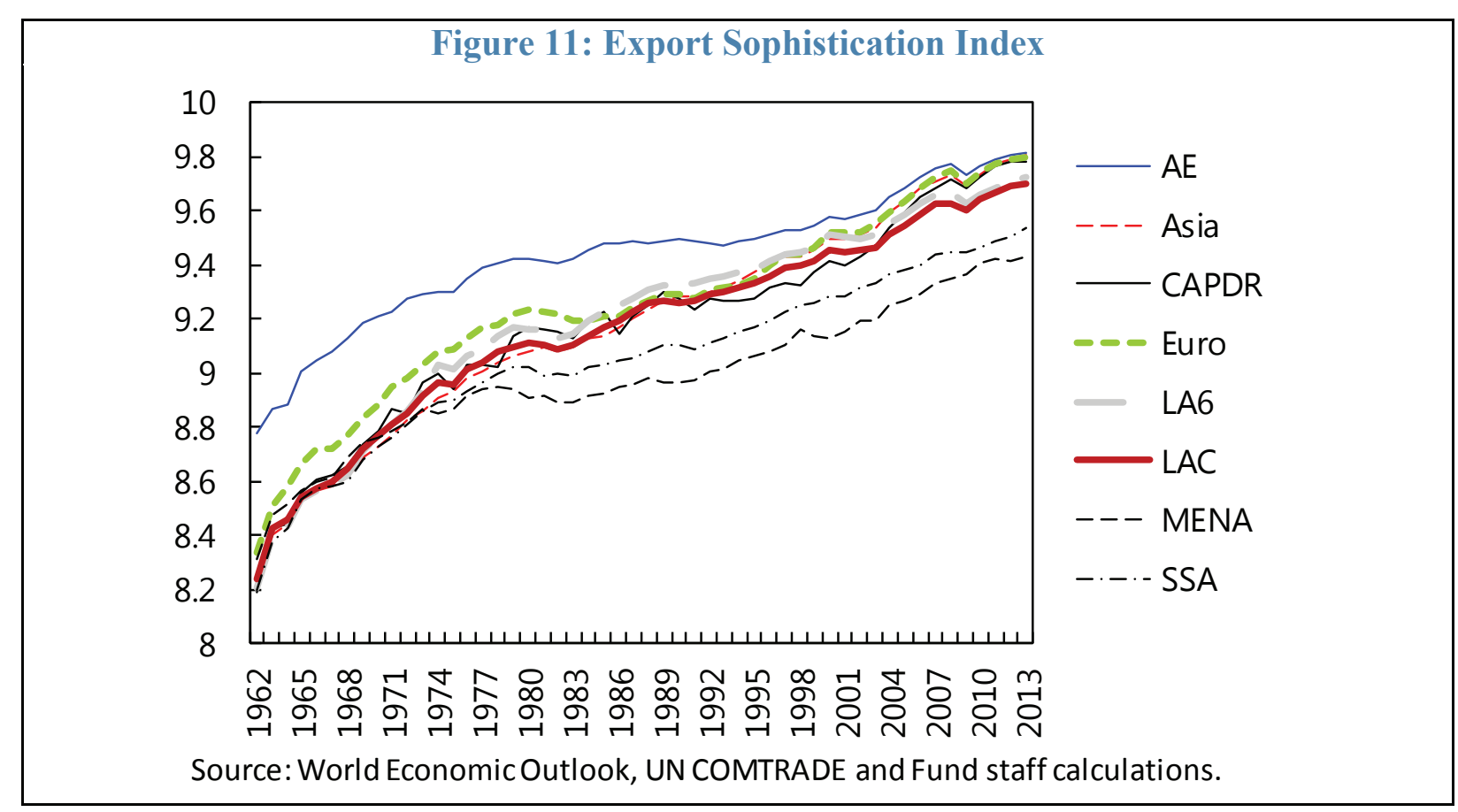

The rising trend of the export sophistication index for all major regions presented in reflects, to a large extent, the upward trend of GDP per capita (Figure 11). While this index has been widely used in the literature, it may be useful to complement it with a measure that corrects for the trend in GDP per capita ${ }^{20}$. For this purpose, we calculate a "standardized" sophistication index and present the findings in Figure 12. LAC has improved the sophistication of its export portfolio, with most of this development taking place in the 1980s. Similar to the findings in Figure 11, LAC outperformed MENA and Sub-Saharan Africa, but lagged behind Emerging Asia, and did not manage to close the gap with Emerging Europe. Finally, while the countries of LA6 and CAPDR have broadly followed

\footnotetext{
${ }^{19}$ The only period when Emerging Europe fell very close to the level of LAC was in the late 1980s and early 1990s when Emerging Europe was affected by numerous economic challenges and transformations.

${ }^{20}$ For example, see Anand, Kochhar, and Mishra (2015) for similar calculations of the sophistication index.
} 
LAC's trend, the latter group has shown a significant improvement over the last decade, likely linked to the (re)export of more sophisticated products from the special economies zones.

Figure 12: Standardized Export Sophistication Index

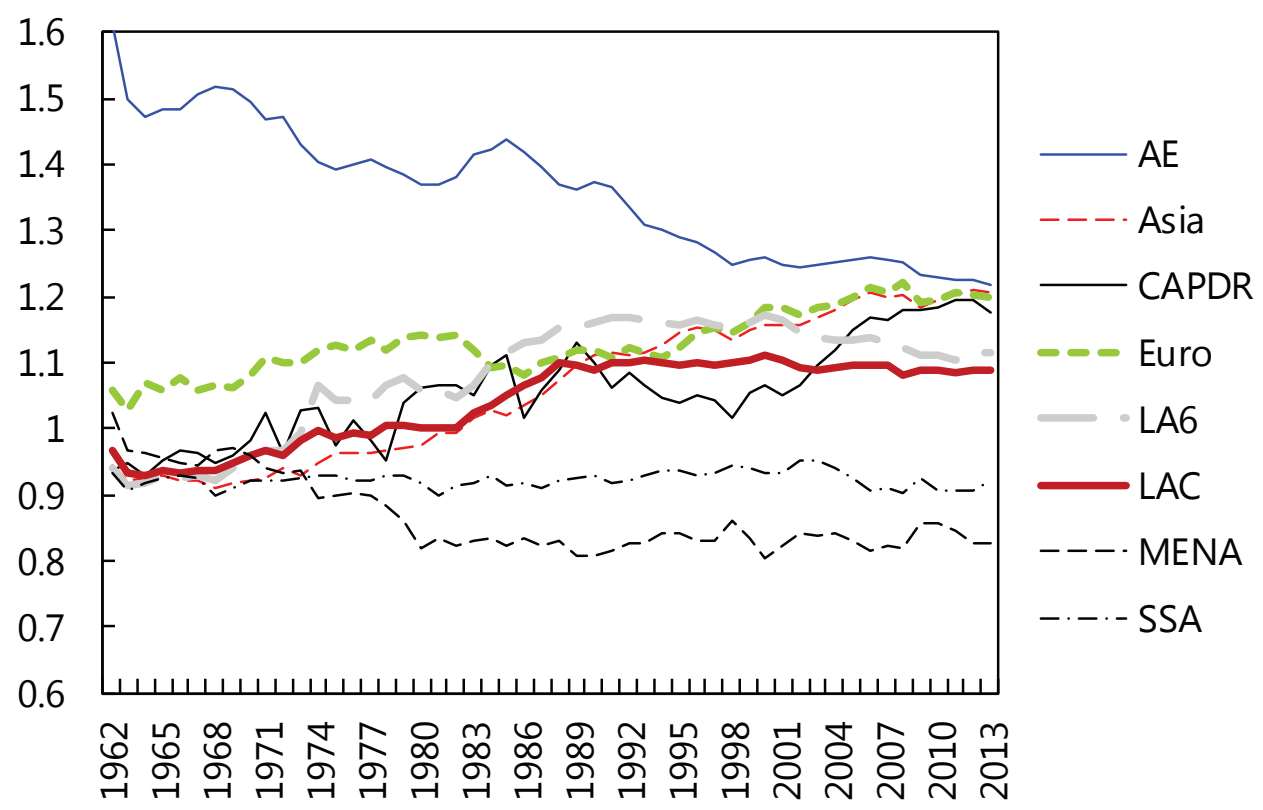

Source: World Economic Outlook, UN COMTRADE and Fund staff calculations.

\section{Economic Complexity}

The evolution of product complexity differed significantly across emerging market regions. Figure 13 depicts the changes in the product complexity of different regions' export portfolios. The export portfolio of LAC countries was quite similar to the portfolio of Emerging Asia in terms of product complexity in the 1960s: least complex products (lowest quintile) accounted for about 75-80 percent of the value of exports in both regions, and the share of most complex products (top quintile) was almost zero. ${ }^{21}$

LAC and Emerging Asia embarked on divergent routes since the late 1990s. LAC and Emerging Asia both followed a trend of increasing complexity till the 1990s and LAC had a significantly larger share of exports that belonged to the top complexity quintile in the mid1990s. However, LAC's trend of increasing export complexity halted in the late 1990s and began reversing since the early 2000s with the commodity price boom - the least complex exports gained and the most complex exports lost share in LAC's portfolio over this period, with the intermediate quintiles showing little change. In contrast, Emerging Asia maintained

${ }^{21}$ The distribution of exports across quintiles is quite robust to the intertemporal movements of certain products across complexity quintiles. The Appendix II contains a similar chart based on recalculation of the quintiles to capture this movement of products across quintiles. 
the trend of declining share for the least complex products, and managed to preserve the share of most complex products over the same period. The most striking difference between the two regions is related to the share of least complex exports: for Emerging Asia this share declined from about 75 percent at the beginning of the 1960s to about 20 percent of total exports in 2013, while for LAC it was only reduced from slightly above 75 percent to about 50 percent over the same period. The other emerging regions, such as MENA and Emerging Europe, started with a different distribution of product complexity, and registered smaller changes in their distributions compared to LAC and Emerging Europe.

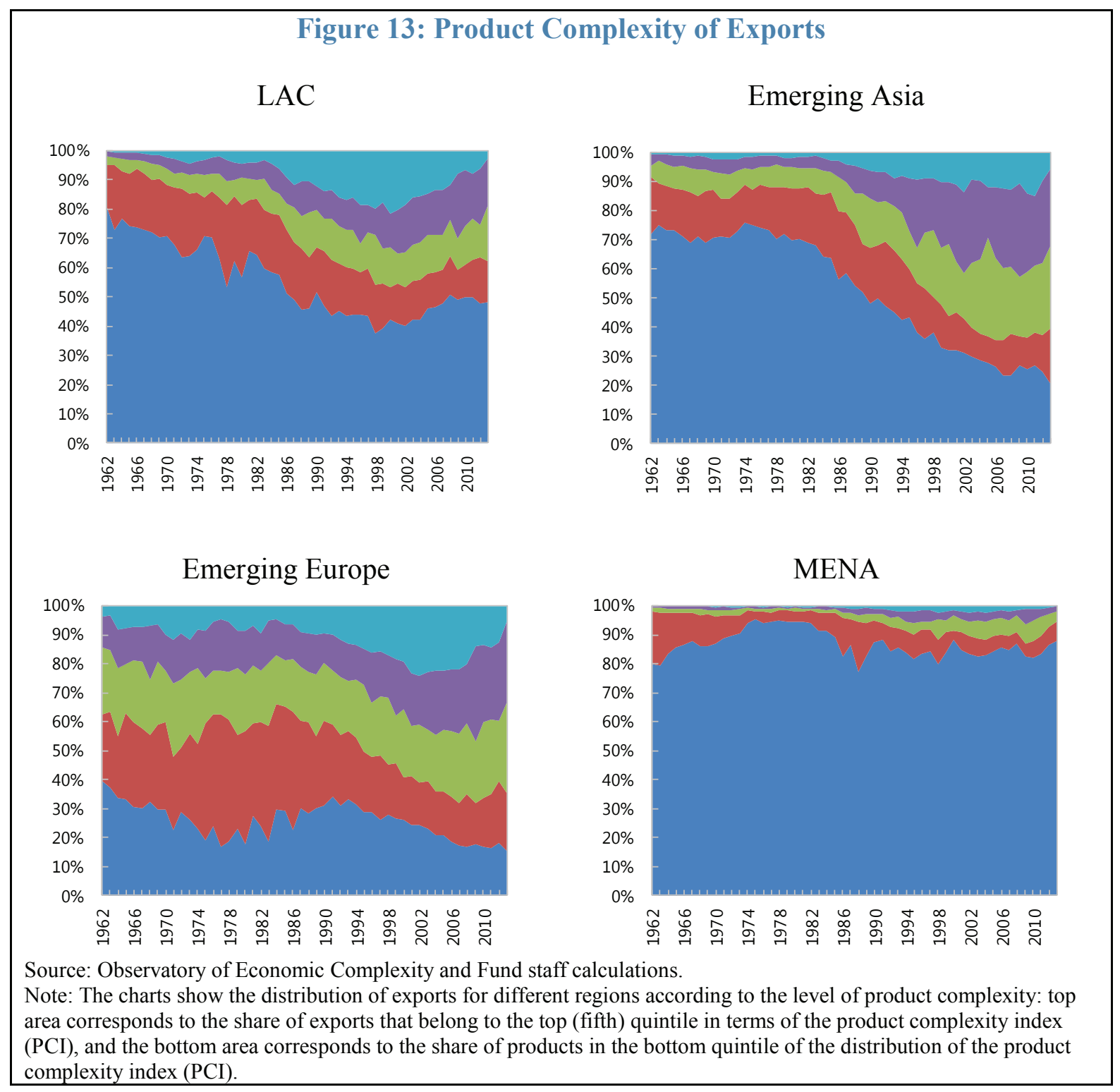




\section{Product Proximity and Predicting Future Composition of Trade}

\section{A. Product Proximity}

The patterns and trends presented in the previous section indicate that the composition of trade for different regions has changed markedly over time. A multitude of different factors, including country/industry characteristics, technological innovations, and policy actions, is likely to have contributed to the shifts into new products and industries as well as the elimination of some old products. In this context, it is particularly important to understand whether the current portfolio of products/exports may reveal some information about the possible future changes in the patterns of trade.

\section{Product proximity as a concept aims to capture the intuition that it is easier for countries to move into industries/products that mostly reuse what they already know or require adding little new productive knowledge. ${ }^{22}$ Therefore, the ability of a country to produce a certain product is expected to depend on how similar or close it is to the country's current production set because similar products are expected to share more characteristics used in production. In turn, such products are more likely to be co-produced, and therefore co-exported, by different countries.}

Formally, product proximity between two products can be measured as the conditional probability of exporting one good given that the other good is also exported. Moreover, the literature typically refers to the co-exporting of goods with a revealed comparative advantage above one, given that this is a stronger concept that better captures the ability to export certain product. Hence, the product proximity between two goods A and B can be defined as:

$$
\operatorname{Proximity}(A, B)=\min \left\{P\left(R C A_{A t} \geq 1 \mid R C A_{B t} \geq 1\right), P\left(R C A_{B t} \geq 1 \mid R C A_{A t} \geq 1\right)\right\}
$$

where, given that conditional probabilities are not symmetric, taking the minimum of the two probabilities reflects a more conservative stance to calculating proximity. ${ }^{23}$

The calculation of product proximity can be illustrated with a concrete example. The proximity between grapes and wine can be deduced on the basis of the set of countries that export them. For instance, if 16 countries export wine with $R C A \geq 1,24$ countries export grapes with $R C A \geq 1$, and 8 countries export both with $R C A \geq 1$, then the proximity between wine and grapes will be calculated as: ${ }^{24}$

\footnotetext{
${ }^{22}$ For a detailed discussion about product proximity and its measurement see Hausmann et al. (2014).

23 Taking the minimum between the two probabilities in this asymmetric case is particularly relevant for minimizing the likelihood of a false relationship when one of the countries is the sole exporter of a certain good with $\mathrm{RCA}>1$.

${ }^{24}$ Note that the proximity is calculated as $8 / 24=0.33$, not as $8 / 16=0.5$ in line with the conservative stance to minimize the chances of false relationship.
} 


$$
\text { Proximity }(\text { wine, grapes })=\frac{P(\text { wine } \cap \text { grapes })}{\max [P(\text { wine }), P(\text { grapes })]}=\frac{8}{24}=0.33
$$

Following the same idea, we calculate the proximity for different product pairs and groups of products over the period 1962-2013. For analytical purposes, we focus on the pairwise proximities between the product groups defined by the degree of skill- and technologyintensity (see classification in Box 1).

\section{B. Predicting Composition of Trade}

Product proximity may provide insights about the future changes in the composition of trade. The previous section showed that proximity between products and groups of products can be calculated on the basis of historical series of exports. Here, we turn our attention to the future and investigate whether the current export portfolio and the proximity between its components can provide some guidance about the likely future changes in the composition of trade. Such predictions are formed on the basis of two elements that are known at present: ${ }^{25}$ first, the distribution of RCAs for the different product groups; and second, all pairwise proximities between these product groups calculated on the basis of historical data. ${ }^{26}$ Using these two pieces of information, we predict the groups of products in which LAC is more likely to gain RCA as follows:

$$
E\left(R C A_{i t}^{g}\right)=\sum_{h=1}^{7} R C A_{i t}^{h} \cdot \operatorname{Proximity}(g, h)
$$

where $g$ and $h$ are product groups, and $E\left(R C A_{i t}^{g}\right)$ is the expected future RCA value for country or region $i$ in product group $g$.

The approach based on product proximity suggests that LAC is likely to lower its export share of commodities and increase its share in skill-intensive goods. Figure 14 presents the latest actual RCAs and the predicted RCAs for LAC. ${ }^{27}$ These findings based on proximity between product groups suggest that LAC as a region is likely to increase its RCA in (low and high) skill- and resource-intensive manufactures and lower its RCA in mineral fuels and primary commodities.

\footnotetext{
25 The present moment here refers to 2013, the latest year with historical data.

${ }^{26}$ Proximities between product groups are calculated from data series for the period 1962-2013. The results are quite robust to alternative sub-periods used in the calculation of product proximities. Appendix III provides a comparison of different time horizons.

27 The actual and predicted values for RCA are standardized, so that they sum to one.
} 


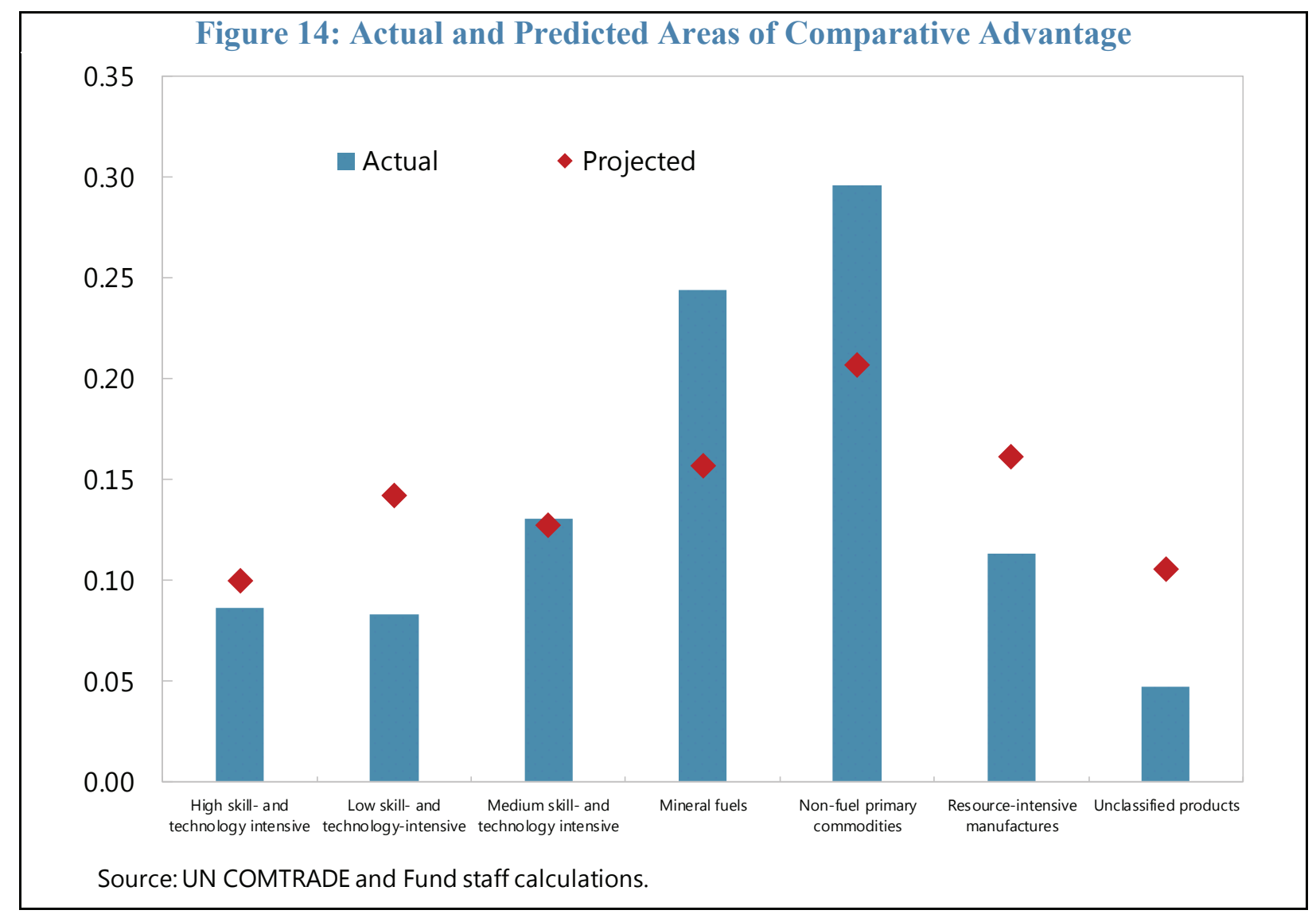

\section{Prediction Performance}

The model based on product proximity predicted well the direction of change in exports for most product categories in LAC. How reliable are these predictions and how well did product proximity predict changes in LAC's comparative advantage in the past? To answer this question, we divide the sample into two sub-periods of equal length: a base period (1962$1987)$ that is used to generate predictions, and a test period (1988-2013) that is used to test those predictions. Figure 15 presents the results from the exercise that tests the accuracy of our predictions. The direction of change in RCAs was correctly projected for six out of seven categories in LAC. In fact, the only anomaly refers to the case of high-skill and technologyintensive products: our method projected that LAC will gain RCA, while LAC's RCA actually declined for this product group. 


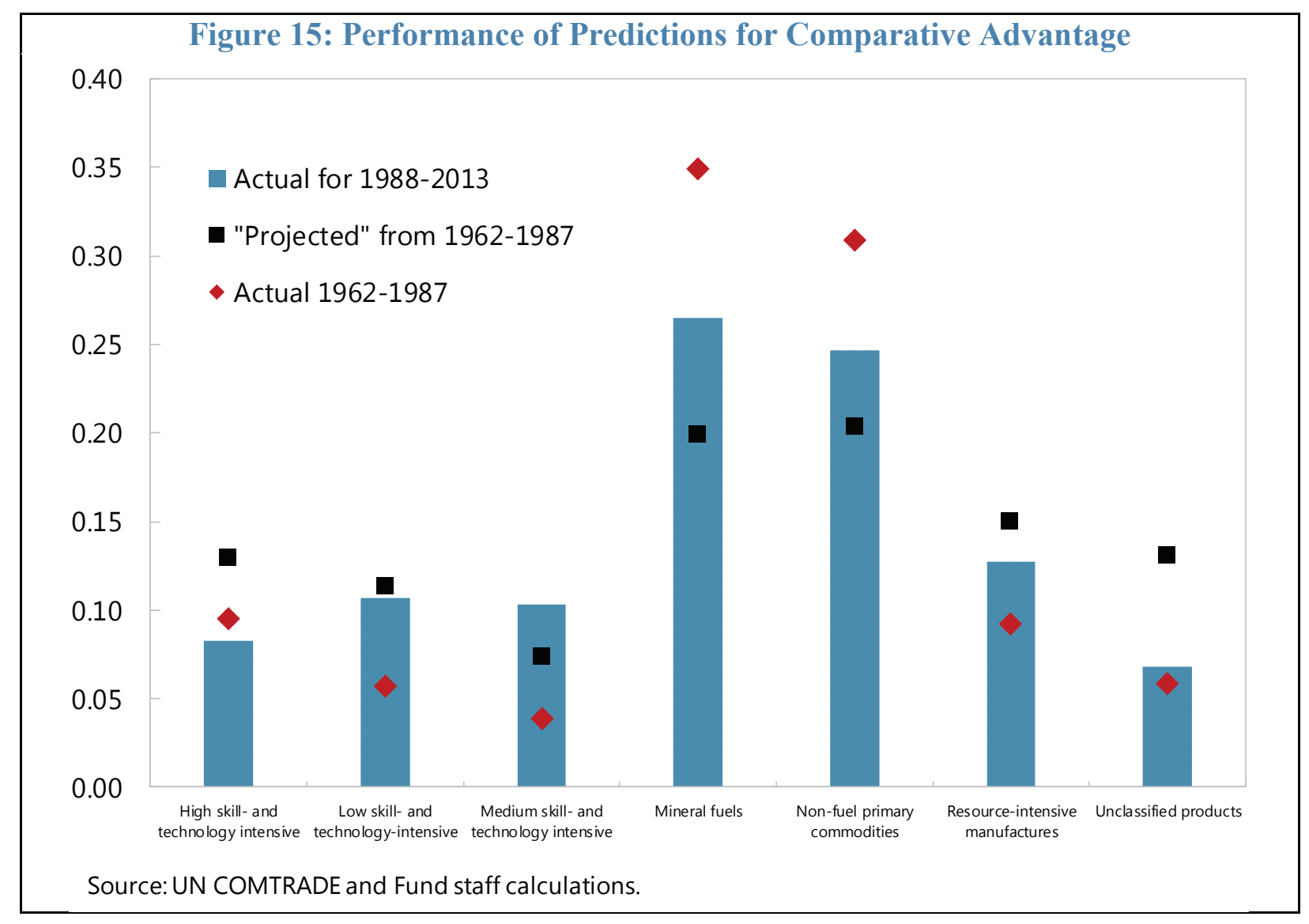

Product proximity, as employed in this analysis, is a static concept that captures the coexporting pattern between products over a certain time period. Here we add dynamics by modifying the way product proximity is measured. Instead of measuring proximity between two products through the probability that these are co-exported with RCA above one, in this case proximity is based on the probability that the RCA of one product increases significantly given the probability that the other product had an average RCA above one. Formally, we use the following equation:

$$
\begin{gathered}
\operatorname{Proximity}(A, B)=\frac{P\left(\widetilde{A_{t, t-5}} \cap \overline{B_{t, t-5}}\right)}{P\left(\overline{B_{t, t-5}}\right)} \\
P\left(\widetilde{A_{t}}\right)=1 \text { if } \Delta R C A>100 \%, P\left(\overline{B_{t}}\right)=1 \text { if } \overline{R C A}>1
\end{gathered}
$$

in this equation proximity between products $\mathrm{A}$ and $\mathrm{B}$ is measured by the conditional probability that RCA for product A has doubled over the past five years given that the average RCA for product B over the same time period has been above one.

Figure 16 presents the prediction results based on this dynamic concept of product proximity. Similar as before, LAC is predicted to gain RCA in low-skill and high-skill and technologyintensive products and lower its RCA in non-fuel primary commodities and, to some extent, in mineral fuels. While the static version suggested that RCA in resource-intensive 
manufactures is also expected to increase for LAC, these results indicate that no significant change is projected for this product category.

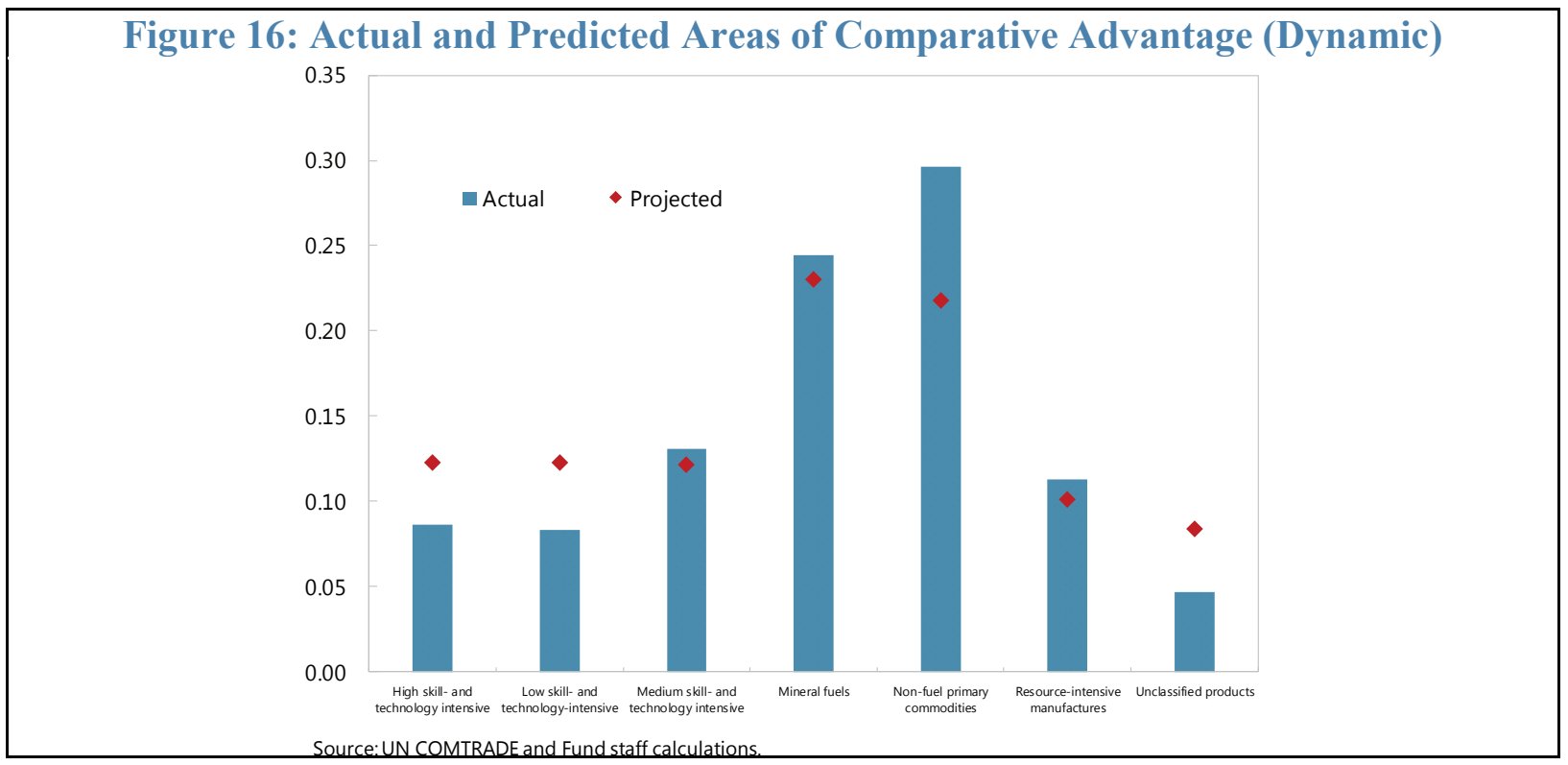

The model based on a dynamic concept of product proximity produces similar results as the static one. The results from a performance check of the predictions derived with this dynamic format are presented in Figure 17. Similar as the static version, this approach has corrected predicted the direction of change in RCA for six out of seven product categories. The only exception remains the group of high skill- and technology-intensive manufactures, where LAC's comparative advantage decreased instead of increasing.

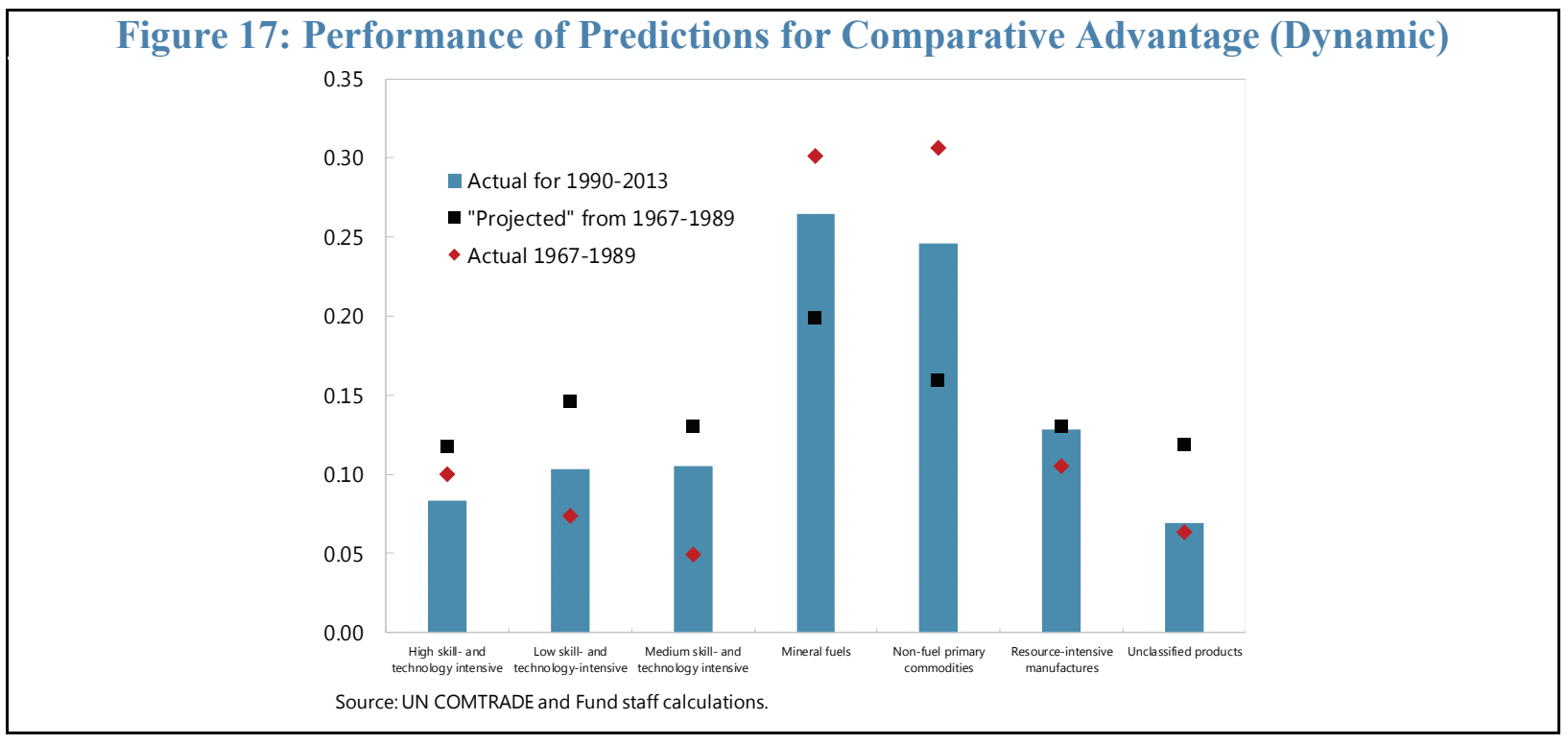

Overall, the prediction method based on product proximity, both in the static and the dynamic version, has correctly projected the direction of change in the pattern of 
RCAs. Such conclusion applies to almost all broad product groups. The anomaly with high skill manufactures remains puzzling, nonetheless, as it may suggest that LAC faced specific constraints and obstacles that prevented the region to increase its comparative advantage in this area. Therefore, we investigate this issue formally with regression analysis in the following section.

\section{REGRESSION ANALYSIS}

\section{Empirical studies have primarily focused on documenting the impact of composition of} trade on economic outcomes. For instance, export sophistication, or the income level associated with a country's export basket and the level of economic complexity have been suggested as important factors that determine future economic growth and differences in income per capita (Hausman, Hwang, and Rodrik, 2007; Hausmann et al. 2014).

This analysis takes one step further and investigate what factors can explain differences in export composition across countries. We are primarily interested in the impact of various policies on economic complexity, as well as on product diversification, sophistication, and the revealed comparative advantage in high-skill products. We include the last two dimensions with the aim to shed some light on the anomalous results for this product group in LAC found in the forecasting exercise in the previous section.

\section{A. Methodology}

We estimate panel regressions given by the following specification:

$$
y_{i t}=\alpha_{i}+\beta X_{i t}+\varepsilon_{i t}
$$

where the dependent variable $y_{i t}$ refers one of the dimensions of trade composition (complexity, product concentration, sophistication, the RCA in high skill- and technology intensive products, or the share of high skill- and technology-intensive products) for country $i$ at time $t$, and $X_{i t}$ stands for the set of explanatory factors: infrastructure quality, average tariffs, enrollment rate in secondary schooling or tertiary education, and Gini index of income inequality. ${ }^{28} \mathrm{We}$ also control for differences in income per capita across countries, and include time fixed effects in order to control for time-specific (global) factors. We include all explanatory variables simultaneously to control for the effect of all factors.

\footnotetext{
${ }^{28}$ Results reported here include the net Gini index, and they are generally consistent with results from regression specifications that include market Gini.
} 


\section{The importance of different factors for export composition is explored using different} procedures. We estimate this specification using several procedures. Besides panel regressions with time fixed effect, we run instrumental variables (IV) regressions, where we instrument the potentially endogenous explanatory variables (infrastructure, education, tariffs, and income inequality) with their lagged values. We also replace these variables with their lags. Given the limited variability across time and the importance of cross-country variation for the issues we want to investigate, we estimate a panel that consists of nonoverlapping 5-year averages as well as a cross section that contains averages for all variables.

\section{B. Results}

Infrastructure quality, education, tariffs, and income inequality are important factors for the composition of exports. Table 1 presents baseline results from the panel estimations. There are several interesting findings. First, better infrastructure quality, lower tariffs, higher school enrollment, and lower income inequality are associated with higher economic complexity. All these variables are statistically significant after controlling for income per capita and explain a very large portion (about 75 percent) of the total variability in the economic complexity index. Second, better infrastructure, lower tariffs, better education, and higher inequality seem to be associated with lower export product concentration (higher export diversification). ${ }^{29}$ Third, higher export sophistication is associated with higher education and lower inequality, while the effect of the other variables does not seem to be robust. Fourth, better infrastructure, higher school enrollment, and more inequality are associated with higher RCA and export share of high skill-intensive products.

\section{The baseline empirical specification may suffer from endogeneity due to simultaneous} causality between the dimensions of trade composition and the explanatory variables as well as possible existence of some unaccounted confounding factors. ${ }^{30}$ To address endogeneity concerns, we estimate the regression equation using instrumental variables (IV) procedure and present the results in Table $2 .{ }^{31}$ Findings seem to be broadly consistent with those in Table 1, though some effects lose their statistical significance. As before, better infrastructure, lower tariffs, better education and lower inequality seem to be related to more complex exports. Second, higher tariffs increase export product concentration, but the other policy variables do not seem robust. Third, and in contrast to the specification without IVs, export sophistication seems associated with better infrastructure, lower tariffs, better

\footnotetext{
${ }^{29}$ The finding that education is a strong and robust determinant of export concentration (diversification) is consistent with the results for the role of human capital for export diversification in Agosin, Alvarez, and Bravo-Ortega (2011).

${ }^{30}$ In Appendix V we also present results from panel VAR that accounts for possible reverse causality and provides a richer representation of the dynamic interactions among the variables of interest.

${ }^{31}$ The under-identification test for the instruments is rejected and the Sargan-Hansen test for over-identifying restrictions in not rejected.
} 
education and lower inequality (though the latter two effects are not very robust). ${ }^{32}$ Fourth, better infrastructure quality and better education (measured by enrollment in tertiary education) raise the comparative advantage and the export share of high skill- and technology-intensive products. In this regard, countries with higher export share of such products also seem to be relatively more unequal.

\begin{tabular}{|c|c|c|c|c|c|c|c|c|c|c|}
\hline & \multicolumn{2}{|c|}{$\begin{array}{r}\mathrm{T} \\
\text { complexity } \\
\end{array}$} & \multicolumn{2}{|c|}{ concentration } & \multicolumn{2}{|c|}{ sophistication } & \multicolumn{2}{|c|}{ RCA in high-skill products } & \multicolumn{2}{|c|}{ share of high-skill products } \\
\hline & 1 & II & III & IV & $\mathrm{V}$ & $\mathrm{VI}$ & VII & VIII & IX & $\mathrm{x}$ \\
\hline Infrastructure & $\begin{array}{l}7.747^{* * *} \\
(0)\end{array}$ & $\begin{array}{l}11.06^{* * *} \\
(0)\end{array}$ & $\begin{array}{l}-0.0826 \\
(0.573)\end{array}$ & $\begin{array}{l}-0.237^{*} \\
(0.0951)\end{array}$ & $\begin{array}{l}-0.266^{*} \\
(0.0711)\end{array}$ & $\begin{array}{l}0.136 \\
(0.385)\end{array}$ & $\begin{array}{l}2.810 * * * \\
(1.36 \mathrm{e}-05)\end{array}$ & $\begin{array}{l}4.346 * * * \\
(0)\end{array}$ & $\begin{array}{l}0.733^{* * *} \\
(3.98 \mathrm{e}-05)\end{array}$ & $\begin{array}{l}1.166^{* * *} \\
(0)\end{array}$ \\
\hline Tariffs & $\begin{array}{l}-0.00568^{* *} \\
(0.0384)\end{array}$ & $\begin{array}{l}-0.0317^{* * *} \\
(0)\end{array}$ & $\begin{array}{l}0.00231 * * * \\
(0.000127)\end{array}$ & $\begin{array}{l}0.00304^{* * *} \\
(7.57 \mathrm{e}-10)\end{array}$ & $\begin{array}{l}0.00373^{* * *} \\
(9.49 \mathrm{e}-10)\end{array}$ & $\begin{array}{l}-0.000469 \\
(0.386)\end{array}$ & $\begin{array}{l}0.00375 \\
(0.138)\end{array}$ & $\begin{array}{l}-0.00286 \\
(0.175)\end{array}$ & $\begin{array}{l}0.00100 \\
(0.151)\end{array}$ & $\begin{array}{l}-0.000816 \\
(0.161)\end{array}$ \\
\hline Education & $\begin{array}{l}0.00275^{* *} \\
(0.0219)\end{array}$ & $\begin{array}{l}0.00512 * * * \\
(0.00103)\end{array}$ & $\begin{array}{l}-0.000873^{* * *} \\
(0.000930)\end{array}$ & $\begin{array}{c}*-0.000973 * * * \\
(0.000163)\end{array}$ & $\begin{array}{l}0.000617^{* *} \\
(0.0197)\end{array}$ & $\begin{array}{l}0.000893^{* * *} \\
(0.00172)\end{array}$ & $\begin{array}{l}0.0156^{* * *} \\
(0)\end{array}$ & $\begin{array}{l}0.0225^{* * *} \\
(0)\end{array}$ & $\begin{array}{l}0.00428 * * * \\
(0)\end{array}$ & $\begin{array}{l}0.00624 * * * \\
(0)\end{array}$ \\
\hline Gini Index & $\begin{array}{l}-0.00479 * \\
(0.0888)\end{array}$ & $\begin{array}{l}-0.0217^{* * *} \\
(1.58 \mathrm{e}-09)\end{array}$ & $\begin{array}{l}-0.00259 * * * \\
(2.90 \mathrm{e}-05)\end{array}$ & $\begin{array}{l}-0.00180 * * * \\
(0.00225)\end{array}$ & $\begin{array}{l}-0.00146^{* *} \\
(0.0183)\end{array}$ & $\begin{array}{l}-0.00357^{* * *} \\
(5.19 \mathrm{e}-08)\end{array}$ & $\begin{array}{l}0.0106 * * * \\
(6.11 \mathrm{e}-05)\end{array}$ & $\begin{array}{l}0.00891 * * * \\
(0.000531)\end{array}$ & $\begin{array}{l}0.00291^{* * *} \\
(7.29 \mathrm{e}-05)\end{array}$ & $\begin{array}{l}0.00237^{* * *} \\
(0.000831)\end{array}$ \\
\hline Income per capita & $\begin{array}{l}0.656^{* * *} \\
(0)\end{array}$ & & $\begin{array}{l}-0.0277^{* * *} \\
(2.21 \mathrm{e}-07)\end{array}$ & & $\begin{array}{l}0.0823 * * * \\
(0)\end{array}$ & & $\begin{array}{l}0.181^{* * *} \\
(0)\end{array}$ & & $\begin{array}{l}0.0514 * * * \\
(0)\end{array}$ & \\
\hline Constant & $\begin{array}{l}-5.412 * * * \\
(0)\end{array}$ & $\begin{array}{l}1.408^{* * *} \\
(3.46 \mathrm{e}-10) \\
\end{array}$ & $\begin{array}{l}0.587^{* * *} \\
(0) \\
\end{array}$ & $\begin{array}{l}0.318^{* * *} \\
(0)\end{array}$ & $\begin{array}{l}3.52 \mathrm{e}-05 \\
(1.000) \\
\end{array}$ & $\begin{array}{l}0.888^{* * *} \\
(0)\end{array}$ & $\begin{array}{l}-1.569 * * * \\
(1.18 \mathrm{e}-07) \\
\end{array}$ & $\begin{array}{l}0.177 \\
(0.250) \\
\end{array}$ & $\begin{array}{l}-0.471^{* * *} \\
(9.50 \mathrm{e}-09) \\
\end{array}$ & $\begin{array}{l}0.0339 \\
(0.426) \\
\end{array}$ \\
\hline $\begin{array}{l}\text { Observations } \\
\text { R-squared }\end{array}$ & $\begin{array}{l}990 \\
0.751 \\
\end{array}$ & $\begin{array}{l}1,049 \\
0.551 \\
\end{array}$ & $\begin{array}{l}990 \\
0.160 \\
\end{array}$ & $\begin{array}{l}1,049 \\
0.131 \\
\end{array}$ & $\begin{array}{l}990 \\
0.312 \\
\end{array}$ & $\begin{array}{l}1,049 \\
0.146 \\
\end{array}$ & $\begin{array}{l}990 \\
0.254 \\
\end{array}$ & $\begin{array}{l}1,049 \\
0.224 \\
\end{array}$ & $\begin{array}{l}990 \\
0.256 \\
\end{array}$ & $\begin{array}{l}1,049 \\
0.225 \\
\end{array}$ \\
\hline $\begin{array}{l}\text { pval in parenthese } \\
* * * p<0.01, * * p<0 . \\
\text { Note: Estimation re } \\
\text { refer to average ap } \\
\text { education in regres }\end{array}$ & $\begin{array}{l},^{*} p<0.1 \\
\text { ults from pa } \\
\text { lied tariffs } r\end{array}$ & I regression & hat include & me fixed effe & ts. Infrastruc & re is measur & d by the der & $y$ of the rai & lay network $\mathrm{f}$ & $\begin{array}{l}\text { he WDI, tariffs } \\
\text { th tertiary }\end{array}$ \\
\hline
\end{tabular}

Table 2: Determinants of the Composition of Trade: IV Regressions

\begin{tabular}{|c|c|c|c|c|c|c|c|c|c|c|}
\hline & \multicolumn{2}{|c|}{ complexity } & \multicolumn{2}{|c|}{ concentration } & \multicolumn{2}{|c|}{ sophistication } & \multicolumn{2}{|c|}{ RCA in high-skill products } & \multicolumn{2}{|c|}{ share of high-skill products } \\
\hline & 1 & II & III & IV & $\mathrm{V}$ & $\mathrm{VI}$ & VII & VIII & $\mathrm{IX}$ & $\mathrm{x}$ \\
\hline \multirow[t]{2}{*}{ Infrastructure } & $4.869 * * *$ & $8.017^{* * *}$ & 0.174 & 0.113 & 0.186 & $0.401^{* *}$ & $3.137^{* * *}$ & $4.301^{* * *}$ & $0.811^{* * *}$ & $1.127^{* * *}$ \\
\hline & $(0.000667)$ & $(5.85 \mathrm{e}-07)$ & $(0.405)$ & $(0.559)$ & $(0.306)$ & $(0.0457)$ & $(0.000688)$ & $(5.90 e-08)$ & $(0.00138)$ & $(1.90 e-07)$ \\
\hline \multirow[t]{2}{*}{ Tariffs } & 0.0105 & $-0.0622 * * *$ & 0.00381 & $0.00549 * *$ & 0.00172 & $-0.00491 * * *$ & 0.0121 & -0.00153 & 0.00312 & -0.000592 \\
\hline & $(0.246)$ & $(1.33 e-06)$ & $(0.100)$ & $(0.0152)$ & $(0.369)$ & $(0.000981)$ & $(0.188)$ & $(0.862)$ & $(0.224)$ & $(0.808)$ \\
\hline \multirow[t]{2}{*}{ Education } & $0.00525^{* *}$ & -0.00165 & -0.000320 & -0.000197 & $0.000584 *$ & $7.32 \mathrm{e}-05$ & $0.0227^{* * *}$ & $0.0291 * * *$ & $0.00625^{* * *}$ & $0.00799 * * *$ \\
\hline & $(0.0251)$ & $(0.581)$ & $(0.408)$ & $(0.565)$ & $(0.0864)$ & $(0.844)$ & $(9.94 \mathrm{e}-05)$ & $(3.34 \mathrm{e}-08)$ & $(8.94 \mathrm{e}-05)$ & $(2.00 \mathrm{e}-08)$ \\
\hline \multirow[t]{2}{*}{ Gini Index } & -0.00952 & $-0.0230 * * *$ & $-0.00160 *$ & -0.00137 & -0.00122 & $-0.00263^{* *}$ & $0.0175^{* * *}$ & $0.0161^{* * *}$ & $0.00486 * * *$ & $0.00446 * * *$ \\
\hline & $(0.107)$ & $(0.00239)$ & $(0.0921)$ & $(0.160)$ & $(0.180)$ & $(0.0121)$ & $(0.000716)$ & $(0.000967)$ & $(0.000602)$ & $(0.000850)$ \\
\hline \multirow[t]{2}{*}{ Income per capita } & $0.765^{* * *}$ & & -0.0192 & & $0.0656 * * *$ & & $0.206^{* * *}$ & & $0.0563 * * *$ & \\
\hline & $(0)$ & & $(0.158)$ & & $(5.04 \mathrm{e}-11)$ & & $(0.00160)$ & & $(0.00262)$ & \\
\hline \multirow[t]{2}{*}{ Constant } & $-7.167 * * *$ & $1.576^{* * *}$ & $0.485^{* * *}$ & $0.269 * * *$ & $0.201 *$ & $0.953 * * *$ & $-2.575^{* * *}$ & $-0.590 * * *$ & $-0.715^{* * *}$ & $-0.169 * * *$ \\
\hline & (0) & $(2.48 \mathrm{e}-06)$ & $(0.00198)$ & (0) & $(0.0642)$ & (0) & $(8.05 e-06)$ & $(0.00230)$ & $(1.48 \mathrm{e}-05)$ & $(0.00144)$ \\
\hline Observations & 688 & 708 & 688 & 708 & 688 & 708 & 688 & 708 & 688 & 708 \\
\hline R-squared & 0.696 & 0.457 & 0.096 & 0.083 & 0.382 & 0.249 & 0.284 & 0.258 & 0.294 & 0.271 \\
\hline
\end{tabular}

pval in parentheses

$* * * p<0.01, * * p<0.05, * p<0.1$

Note: Estimation results from instrumental variables (IV) panel regressions that include time fixed effects. Infrastructure, tariffs, education, and Gini index are instrumented by their first two lags. Infrastructure is measured by the density of the railway network from the WDI, tariffs refer to average applied tariffs retrieved from the WITS database, education refers to secondary school enrollment rate and to share of population with tertiary education in regressions for RCA and share of high-skill products, and income inequality is measured by the net Gini index from the SWIID.

${ }^{32}$ In turn, the findings in column (VI) suggests that accounting for endogeneity, which may be particularly critical for export sophistication that directly depends on income per capita by construction, leads to more intuitive results. 
Overall, our empirical findings based on alternative estimation procedures suggest that all considered policy-related variables play important roles in determining aspects of the trade composition and explaining cross-country differences. ${ }^{33}$ Moreover, these effects are generally significant when included simultaneously, suggesting that each policy-related aspect has its own weight. Infrastructure is found to be an important factor for complexity, sophistication, and the share of high-skill products. The level of average tariffs, as one element of trade policy, is negatively associated with economic complexity, product diversification and sophistication. Finally, education outcomes are positively associated with economic complexity, sophistication, and the export share and comparative advantage in high-skill products.

\section{IMPACT OF TRADE AgREementS}

Trade agreements are likely to generate growth in exports, but may also result in wideranging structural changes in the economies affected that could have an impact on the composition of their export baskets. ${ }^{34}$ Figure 18 presents event studies about the impact of major regional trade agreements that involve LAC countries, such as the Andean Community, CAFTA-DR, Mercosur, and NAFTA on key dimensions of trade composition. The visual evidence in Figure 18 suggests prima facie that: complexity increased somewhat after Mercosur, with little changes associated with the other agreements; export concentration declined after the entrance into force of the Andean Community, CAFTA-DR and Mercosur, while it seems to have increased after NAFTA; export sophistication seems to have increased sharply in the immediate period after the Andean Community, with little changes associated with the other agreements.

\footnotetext{
${ }^{33}$ Appendix IV presents results from panel regressions, where the panel is constructed from average values for 5-year non-overlapping periods. It also contains results from cross-section estimations based on country averages.

34 See Hannan (2016) for an ex-post study of the impact of trade agreements on export growth. Kohl, Brakman, and Garretsen (2016) document the heterogeneity of the impact of trade agreements.
} 


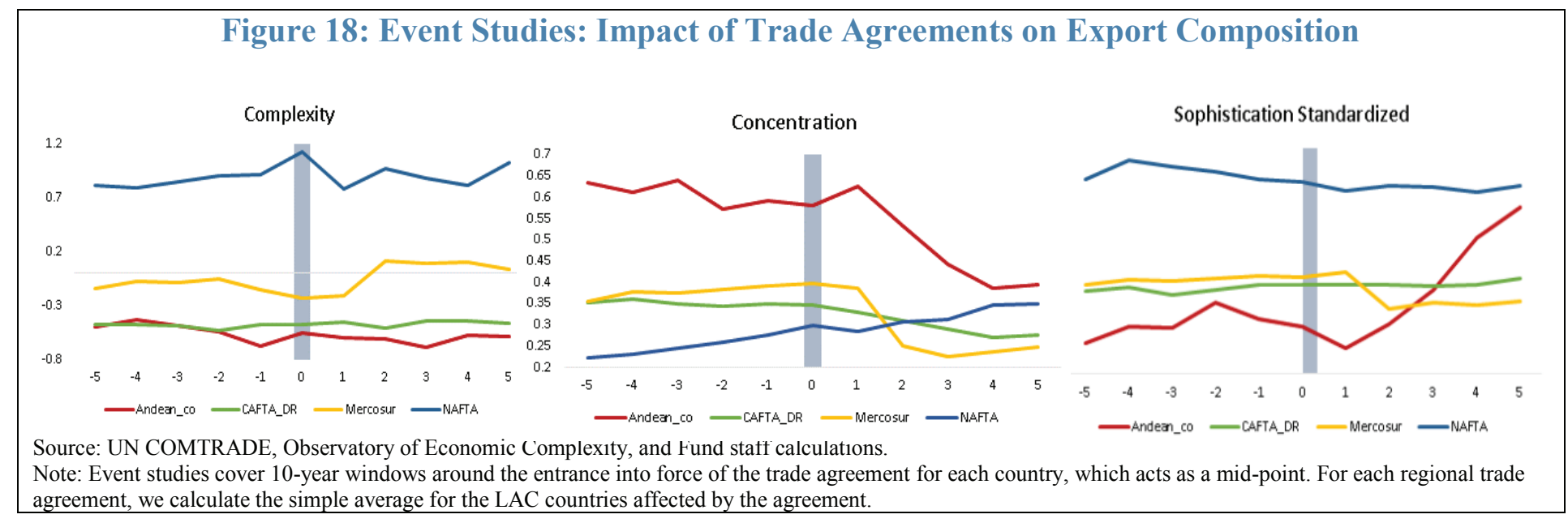

Major regional trade agreements in LAC with associated with significant changes in the composition of exports. Beyond the visual evidence in Figure 18, we investigate formally whether the entrance into force of certain trade agreement led to a significant change in the composition of trade. The results in Table 3 convey several messages: first, all agreements were associated with higher export sophistication ex-post. Second, the agreements were generally associated with lower product concentration (higher product diversification), with the exception of NAFTA. Third, NAFTA led to both higher complexity and higher product concentration in Mexico, likely as a result of the expansion of the manufacturing sector in a very specific direction. Fourth, CAFTA-DR seems to be the only agreement associated with lower export complexity ex-post, which possibly reflects the maquila expansion into garment and footwear in the immediate post-agreement period.

Table 3: Regression Results: Impact of Trade Agreements on Export Composition Regression results: Impact of trade agreements

\begin{tabular}{|c|c|c|c|}
\hline & complexity & concentration & sophistication \\
\hline \multirow[t]{2}{*}{ Mercosur } & 0.0780 & $-0.207 * * *$ & $0.187^{* *}$ \\
\hline & $(0.200)$ & (0) & $(0.0187)$ \\
\hline \multirow[t]{2}{*}{ NAFTA } & $0.321 * * *$ & $0.0750 * * *$ & $0.415^{* * *}$ \\
\hline & $(2.16 \mathrm{e}-05)$ & $(1.43 e-05)$ & $(0.000370)$ \\
\hline \multirow[t]{2}{*}{ CAFTA-DR } & $-0.270 * * *$ & $-0.158 * * *$ & $0.682^{* * *}$ \\
\hline & (3.90e-05) & (0) & (0) \\
\hline \multirow[t]{2}{*}{ Andean community } & 0.0670 & $-0.240 * * *$ & $0.731 * * *$ \\
\hline & $(0.504)$ & (0) & (0) \\
\hline \multicolumn{4}{|c|}{ pval in parentheses } \\
\hline \multicolumn{4}{|c|}{$* * * p<0.01, * * p<0.05, * p<0.1$} \\
\hline \multicolumn{4}{|c|}{$\begin{array}{l}\text { Note: Results from regressing indicators for different dimensions of } \\
\text { trade composition on dummy variables that correspond to time when the } \\
\text { trade agreement entered into force. }\end{array}$} \\
\hline
\end{tabular}




\section{COnCluding Remarks}

The analysis of LAC's composition of trade resembles a journey through the region's economic and social history over the last half a century. This "history reader" takes stock of key trends and patterns in trade composition, investigates the importance of different policy factors, and proposes a method to predict the future changes in LAC's composition of trade. In this section, the analysis provides some concluding remarks and policy recommendations.

First, our documentation of trends and patterns in LAC's trade over half a century demonstrate that numerous and multidimensional factors have shaped the composition of trade. Some of the most prominent include commodity price shocks, gradual decline in the relative importance of the agriculture sector, industrialization policies, expansion of the maquila sector in the special economic zones, discoveries and new exploitations of natural resources, and declines in production of commodities, sometimes related to the broader socio-political context (episodes in Venezuela).

Second, changes in LAC's revealed comparative advantage across product groups have been limited. The LAC region has consistently maintained a revealed comparative advantage in mineral fuels and non-fuel primary commodities over the past half a century, but the region did not manage to establish comparative advantage in any group of skill- and technology-intensive manufactures. This stands in contrast to Emerging Asia, a region that had lower RCA than LAC till the mid-1980s in these products, but followed a trend of continued improvement over the entire period. LAC's comparative advantage has also been limited to less product categories compared to other emerging market regions.

Third, overall export portfolio is one of the most diversified among major regions, though this development is largely driven by Brazil and Mexico. The two largest economies in the region have broad and diversified production and export bases. In addition, large differences persist among countries in LAC, with the group of Caribbean showing high and variable levels of product concentration, which is unsurprising given the small size of those economies.

Fourth, LAC followed a trend of increasing export complexity and sophistication till the late 1990s, which was interrupted and reversed somewhat by the commodity boom in the 2000s. On the other hand, less natural resource-dependent regions, such as Emerging Asia, followed an uninterrupted upward trend on both dimensions.

Fifth, product proximity suggests that LAC is likely to increase the share of skillintensive goods and lower the share of commodities. We show that LAC as a region is likely to increase its comparative advantage in skill- and resource-intensive manufactures and lower its comparative advantage in mineral fuels and primary commodities. Our method correctly predicted the direction of change in all categories, except in high-skill products, where LAC experienced a drop instead of an increase in its comparative advantage. 
Finally, policy factors play an important role in determining the composition of trade. In general, the regression analysis suggests that better infrastructure quality, lower tariffs, higher educational enrollment, and lower inequality are associated with more complex exports. Policies that improve access to higher education, and enhance infrastructure quality are also found to have a significantly positive effect on the export share and comparative advantage in high-skill and technology-intensive products. In this context, effective policy strategies to tackle LAC's underperformance or "deficit" in high-skill products, as suggested in our prediction exercise, will likely need to primarily address challenges in infrastructure and the higher education system. 


\section{REFERENCES}

Anand, R., K. Kochhar, and S. Mishra, 201, "Make in India: Which Exports Can Drive the Next Wave of Growth?," IMF Working Paper 15/119.

Andrews, D. W. K., and B. Lu, 2001, "Consistent Model and Moment Selection Procedures for GMM Estimation with Application to Dynamic Panel Data Models," Journal of Econometrics, 101, 123-164.

Agosin, M. R., R. Alvarez, and C. Bravo-Ortega, 2011, "Determinants of Export Diversification Around the World: 1962-2000”, The World Economy, 35, 295-315.

Arellano, M. and Bond, S., 1991, "Some tests of Specification for Panel data: Monte Carlo evidence and an Application to Employment Equations, Review of Economic Studies," 58, 277-297.

Balassa, B., 1965, "Trade Liberalization and "Revealed" Comparative Advantage," The Manchester School, 33, 99-123.

Banerjee, A. and K. Munshi, 2004, "How Efficiently Is Capital Allocated? Evidence from the Knitted Garment Industry in Tirupur," Review of Economic Studies, 71, 19-42.

Basu, S.R., \& Das, M., 2011, Export Structure and Economic Performance in Developing Countries: Evidence from Nonparametric Methodology. Policy Issues in International Trade and Commodities Study Series, No. 48. Geneva: United Nations Conference on Trade and Development.

Basu, S.R., (forthcoming), Retooling Trade Policy in Developing Countries: Does Technology Intensity of Exports Matter for GDP Per Capita? Policy Issues in International Trade and Commodities Study Series, No. 57. Geneva: United Nations Conference on Trade and Development.

Canova, F. and M. Ciccarelli, 2013, "Panel Vector Autoregressive Models: A Survey,” ECB Working Paper Series 1507.

Hannan, S. A., 2016, "The Impact of Trade Agreements: New Approach, New Insights," IMF Working Paper 16/117.

Hausmann, R., J. Hwang, and D. Rodrik, 2007, "What You Export Matters," Journal of Economic Growth, 12, 1-25.

Hausmann, R., C.A. Hidalgo, S. Bustos, M. Coscia, A. Simoes, and M. A. Yildirim, 2014, The Atlas of Economic Complexity: Mapping Paths to Prosperity, MIT Press.

Hidalgo, C. A. and R. Hausmann, 2009, "The Building Blocks of Economic Complexity," Proceedings of the National Academy of Sciences, 106, 10570-10575. 
Kohl, T. S. Brakman, and H. Garretsen, 2016, "Do Trade Agreements Stimulate International Trade Differently? Evidence from 296 Trade Agreements," The World Economy, 39, 97131.

Krugman, P. R., 1979, “Increasing Returns, Monopolistic Competition, and International Trade," Journal of International Economics, 9, 469-479.

Lall, S., 2000, Selective industrial and trade policies in developing countries: theoretical and empirical issues, Queen Elizabeth House Working Paper, No. 48 (Oxford: University of Oxford).

Lall, S., J. Weiss, and J. Zhang, 2005, "The Sophistication of Exports: A New Trade Measure," World Development, 34, 222-237.

Levchenko, A., 2007, “Institutional Quality and International Trade," Review of Economic Studies, 74, 791-819.

Solt, F., 2016, “The Standardized World Income Inequality Database,” Social Science Quarterly, 97, SWIID Version 5.1, July 2016.

United Nations Conference on Trade and Development, 1996, Trade and Development Report 1996: Developing Countries in World Trade, Geneva.

United Nations Conference on Trade and Development, 2002, Trade and Development Report 2002: Developing Countries in World Trade, Geneva. 
APPENDIX I. COUNTRY GROUPINGS

\begin{tabular}{|c|c|c|c|c|c|c|c|c|}
\hline $\begin{array}{l}\text { Advnaced } \\
\text { Economies }\end{array}$ & $\begin{array}{l}\text { Emerging and } \\
\text { Developing } \\
\text { Europe }\end{array}$ & $\begin{array}{c}\text { Emerging and } \\
\text { Developing } \\
\text { Asia }\end{array}$ & $\begin{array}{l}\text { Latin America } \\
\text { and the } \\
\text { Caribbean }\end{array}$ & $\begin{array}{l}\text { Middle East, } \\
\text { North Africa, } \\
\text { Afghanistan, } \\
\text { and Pakistan }\end{array}$ & $\begin{array}{c}\text { Sub-Sahara } \\
\text { Africa }\end{array}$ & LA6 & CAPDR & Caribbean \\
\hline Australia & Albania & Bangladesh & $\begin{array}{l}\text { Antigua and } \\
\text { Barbuda }\end{array}$ & Afghanistan & Angola & Brazil & Costa Rica & $\begin{array}{l}\text { Antigua and } \\
\text { Barbuda }\end{array}$ \\
\hline Austria & $\begin{array}{l}\text { Bosnia and } \\
\text { Herzegovina }\end{array}$ & Bhutan & Argentina & Algeria & Benin & Chile & $\begin{array}{l}\text { Dominican } \\
\text { Republic }\end{array}$ & Bahamas, The \\
\hline Belgium & Bulgaria & $\begin{array}{c}\text { Brunei } \\
\text { Darussalam }\end{array}$ & Bahamas, The & Bahrain & Botswana & Colombia & El Salvador & Barbados \\
\hline Canada & Croatia & Cambodia & Barbados & Djibouti & Burkina Faso & Mexico & Guatemala & Dominica \\
\hline Cyprus & Hungary & China & Belize & Egypt & Burundi & Peru & Honduras & Grenada \\
\hline Czech Republic & Kosovo & Fiji & Bolivia & Iran & Cameroon & Uruguay & Nicaragua & Haiti \\
\hline Denmark & Macedonia & India & Brazil & Iraq & Cabo Verde & & Panama & Jamaica \\
\hline Estonia & Montenegro & Indonesia & Chile & Jordan & $\begin{array}{c}\text { Central African } \\
\text { Republic }\end{array}$ & & & $\begin{array}{l}\text { St. Vincent and } \\
\text { the Grenadines }\end{array}$ \\
\hline Finland & Poland & Kiribati & Colombia & Kuwait & Chad & & & $\begin{array}{c}\text { St. Kitts and } \\
\text { Nevis }\end{array}$ \\
\hline France & Romania & Lao P.D.R. & Costa Rica & Lebanon & Comoros & & & St. Lucia \\
\hline Germany & Serbia & Malaysia & Dominica & Libya & $\begin{array}{c}\text { Democratic } \\
\text { Republic of the } \\
\text { Congo }\end{array}$ & & & $\begin{array}{c}\text { Trinidad and } \\
\text { Tobago }\end{array}$ \\
\hline Greece & Turkey & Maldives & $\begin{array}{l}\text { Dominican } \\
\text { Republic }\end{array}$ & Mauritania & $\begin{array}{c}\text { Congo, } \\
\text { Republic of }\end{array}$ & & & \\
\hline Hong Kong SAR & & $\begin{array}{l}\text { Marshall } \\
\text { Islands }\end{array}$ & Ecuador & Morocco & Côte d'Ivoire & & & \\
\hline Iceland & & Micronesia & EI Salvador & Oman & $\begin{array}{l}\text { Equatorial } \\
\text { Guinea }\end{array}$ & & & \\
\hline Ireland & & Mongolia & Grenada & Pakistan & Eritrea & & & \\
\hline Israel & & Myanmar & Guatemala & Qatar & Ethiopia & & & \\
\hline Italy & & Nepal & Guyana & Saudi Arabia & Gabon & & & \\
\hline Japan & & Palau & Haiti & Sudan & Gambia, The & & & \\
\hline Korea & & $\begin{array}{c}\text { Papua New } \\
\text { Guinea }\end{array}$ & Honduras & Syria & Ghana & & & \\
\hline Latvia & & Philippines & Jamaica & Tunisia & Guinea & & & \\
\hline Lithuania & & Samoa & Mexico & $\begin{array}{l}\text { United Arab } \\
\text { Emirates }\end{array}$ & Guinea-Bissau & & & \\
\hline Luxembourg & & $\begin{array}{l}\text { Solomon } \\
\text { Islands }\end{array}$ & Nicaragua & Yemen & Kenya & & & \\
\hline Malta & & Sri Lanka & Panama & & Lesotho & & & \\
\hline Netherlands & & Thailand & Paraguay & & Liberia & & & \\
\hline New Zealand & & $\begin{array}{l}\text { Timor-Leste, } \\
\text { Dem. Rep. of }\end{array}$ & Peru & & Madagascar & & & \\
\hline Norway & & Tonga & $\begin{array}{l}\text { St. Kitts and } \\
\text { Nevis }\end{array}$ & & Malawi & & & \\
\hline Portugal & & Tuvalu & St. Lucia & & Mali & & & \\
\hline San Marino & & Vanuatu & $\begin{array}{l}\text { St. Vincent and } \\
\text { the Grenadines }\end{array}$ & & Mauritius & & & \\
\hline Singapore & & Vietnam & Suriname & & Mozambique & & & \\
\hline Slovak Republic & & & $\begin{array}{c}\text { Trinidad and } \\
\text { Tobago }\end{array}$ & & Namibia & & & \\
\hline Slovenia & & & Uruguay & & Niger & & & \\
\hline Spain & & & Venezuela & & Nigeria & & & \\
\hline Sweden & & & & & Rwanda & & & \\
\hline Switzerland & & & & & $\begin{array}{l}\text { São Tomé and } \\
\text { Príncipe }\end{array}$ & & & \\
\hline $\begin{array}{c}\text { Taiwan Province } \\
\text { of China }\end{array}$ & & & & & Senegal & & & \\
\hline United Kingdom & & & & & Seychelles & & & \\
\hline \multirow[t]{9}{*}{ United States } & & & & & Sierra Leone & & & \\
\hline & & & & & South Africa & & & \\
\hline & & & & & South Sudan & & & \\
\hline & & & & & Swaziland & & & \\
\hline & & & & & Tanzania & & & \\
\hline & & & & & Togo & & & \\
\hline & & & & & Uganda & & & \\
\hline & & & & & Zambia & & & \\
\hline & & & & & Zimbabwe & & & \\
\hline
\end{tabular}




\section{Appendix II. Distribution of Product Complexity Allowing Movements Across QUINTILES}

\section{Product Complexity of Exports}

LAC

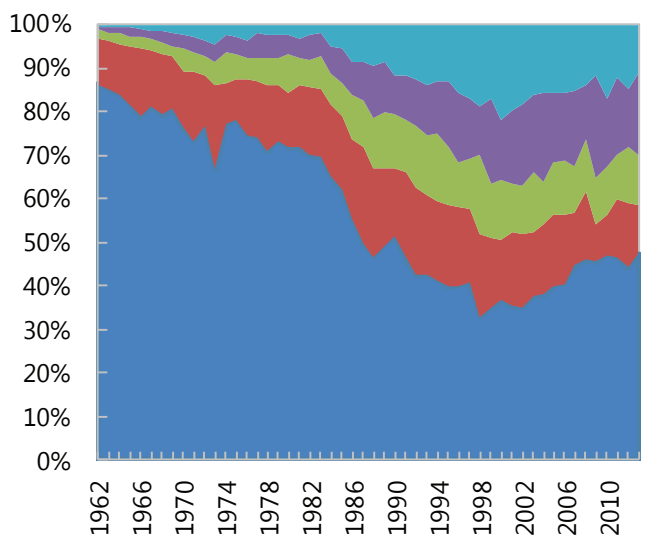

Emerging Europe

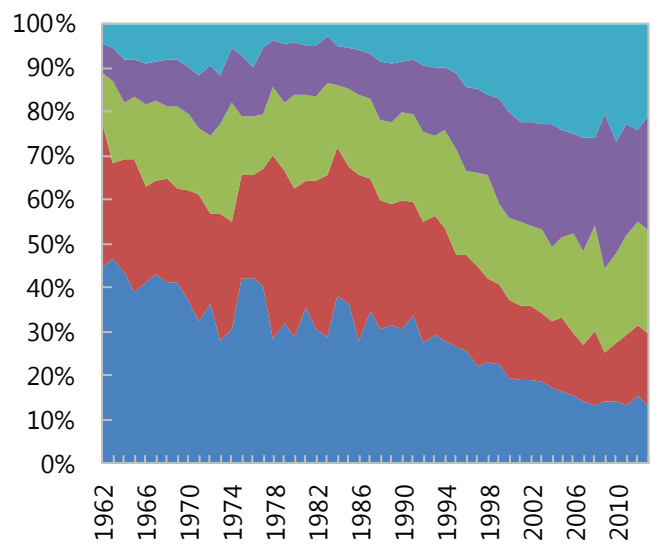

Emerging Asia

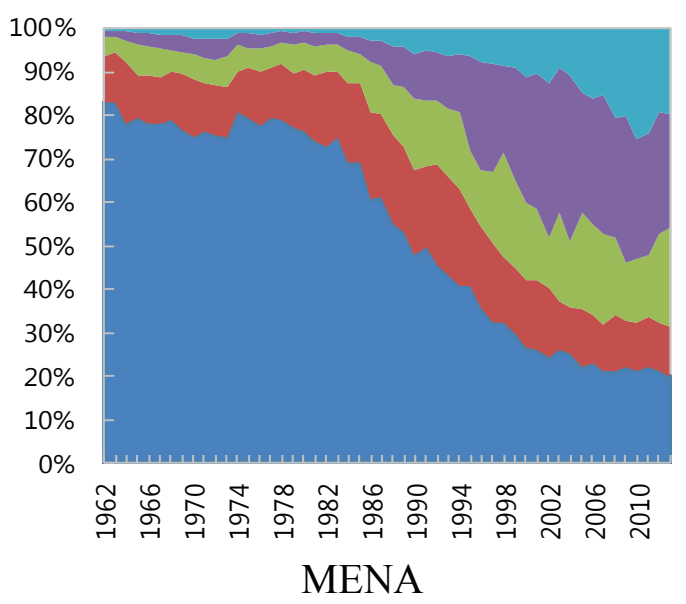

$100 \%$

$90 \%$

$80 \%$

$70 \%$

$60 \%$

$50 \%$

$40 \%$

$30 \%$

$20 \%$

$10 \%$

$0 \%$

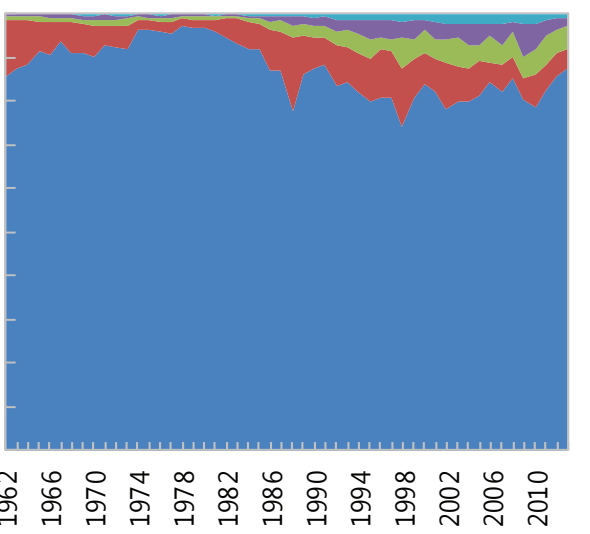

Source: Observatory of Economic Complexity and Fund staff calculations.

Note: The charts show the distribution of exports for different regions according to the level of product complexity: top area corresponds to the share of exports that belong to the top (fifth) quintile in terms of the product complexity index $(\mathrm{PCI})$, and the bottom area corresponds to the share of products in the bottom quintile of the distribution of the product complexity index (PCI). 


\section{Appendix III. Robustness of Predictions for RCAs ACross Product Groups to Alternative Time Horizons}

Different time horizons produce similar "predictions" about the future pattern of RCA across broad product categories, given that product proximity reflects long-lasting structural elements.

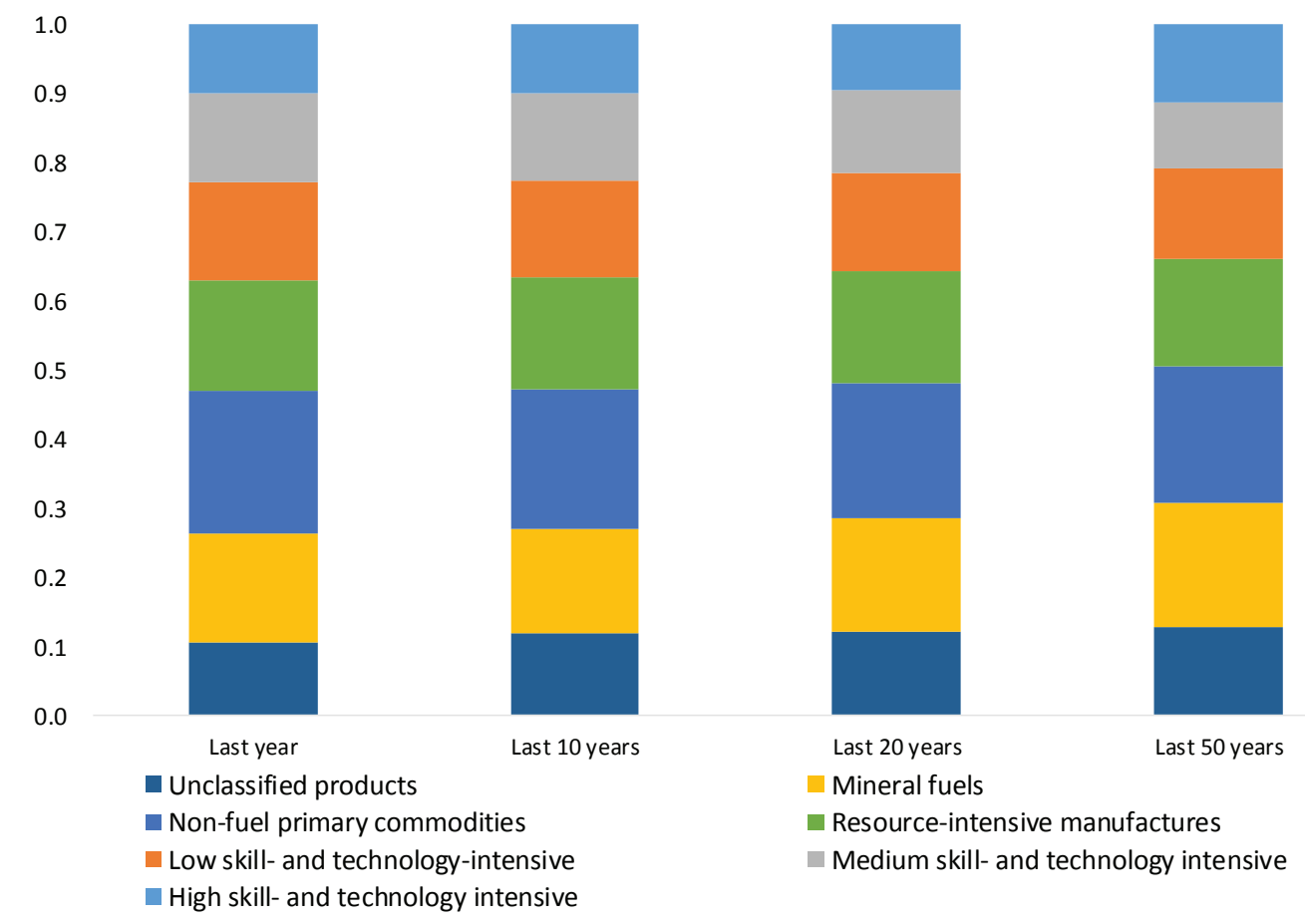

Note: The chart shows the distribution of RCAs across different product categories that are predicted using different time periods. The RCAs for each vintage are standardized, so that they sum to one. 


\section{APPENDIX IV. AdDITIONAL REgRESSION RESUltS}

\section{Appendix IV Table 1. Panel Regression Results (panel dataset based on 5-year averages)}

\begin{tabular}{lllllll}
\hline & \multicolumn{7}{c}{ Panel regression (5-year averages) } \\
\hline \hline Infrastructure & $10.72^{* * *}$ & $15.36^{* * *}$ & -0.491 & $-0.720^{* *}$ & $-0.888^{* * *}$ & -0.153 \\
& $(0)$ & $(0)$ & $(0.105)$ & $(0.0150)$ & $(0.00958)$ & $(0.677)$ \\
Tariffs & $-0.00535^{*}$ & $-0.0232^{* * *}$ & $0.00139^{*}$ & $0.00226^{* * *}$ & $0.00256^{* * *}$ & -0.000237 \\
& $(0.0850)$ & $(3.85 \mathrm{e}-09)$ & $(0.0666)$ & $(0.00158)$ & $(0.00285)$ & $(0.790)$ \\
Education & 0.00302 & $0.00999^{* * *}$ & $-0.00120^{* *}$ & $-0.00150^{* * *}$ & 0.000521 & $0.00139 * *$ \\
& $(0.119)$ & $(7.00 \mathrm{e}-05)$ & $(0.0115)$ & $(0.00125)$ & $(0.327)$ & $(0.0164)$ \\
Gini index & 0.00149 & $-0.0104^{*}$ & $-0.00317^{* * *}$ & $-0.00269 * *$ & -0.00178 & $-0.00399^{* * *}$ \\
& $(0.746)$ & $(0.0837)$ & $(0.00497)$ & $(0.0157)$ & $(0.162)$ & $(0.00425)$ \\
Income per capita & $0.596 * * *$ & & $-0.0283^{* * *}$ & & $0.0926^{* * *}$ & $(0)$ \\
Constant & $(0)$ & & $(0.00145)$ & & -0.0502 & $0.885^{* * *}$ \\
& $-5.187^{* * *}$ & $0.684^{* *}$ & $0.635^{* * *}$ & $0.355^{* * *}$ & $(0.664)$ & $(0)$ \\
\hline Observations & $(0)$ & $(0.0164)$ & $(1.59 \mathrm{e}-09)$ & $(6.19 \mathrm{e}-11)$ & $(0.664)$ & 368 \\
R-squared & 361 & 368 & 361 & 368 & 361 & 0.110 \\
\hline \hline
\end{tabular}

pval in parentheses

$* * * \mathrm{p}<0.01, * * \mathrm{p}<0.05, * \mathrm{p}<0.1$

Note: Estimation results from panel regressions that include time fixed effects. Panel dataset consists of 5year non-overlapping period averages. Infrastructure is measured by the density of the railway network from the WDI, tariffs refer to average applied tariffs retrieved from the WITS database, education refers to secondary school enrollment rate and to share of population with tertiary education in regressions for RCA and share of high-skill products, and income inequality is measured by the net Gini index from the SWIID.

\section{Appendix IV Table 2. Cross-Section Regression Results (based on country averages)}

\begin{tabular}{lllllll}
\multicolumn{7}{c}{ Cross section regression (country averages) } \\
\hline \hline Infrastructure & \multicolumn{2}{c}{ complexity } & \multicolumn{2}{c}{ diversification } & \multicolumn{2}{c}{ sophistication } \\
& $11.65^{* * *}$ & $16.54 * * *$ & -1.046 & $-1.206^{*}$ & -0.940 & 0.562 \\
Tariffs & $(1.35 \mathrm{e}-05)$ & $(1.17 \mathrm{e}-07)$ & $(0.113)$ & $(0.0527)$ & $(0.413)$ & $(0.653)$ \\
& -0.0161 & $-0.0321^{* *}$ & 0.00383 & 0.00430 & $0.0149 * * *$ & $0.00910^{*}$ \\
Education & $(0.131)$ & $(0.0102)$ & $(0.165)$ & $(0.104)$ & $(0.00257)$ & $(0.0902)$ \\
& 0.00265 & $0.0121^{* *}$ & -0.00172 & $-0.00206^{*}$ & 0.00110 & 0.00355 \\
Gini index & $(0.571)$ & $(0.0240)$ & $(0.157)$ & $(0.0707)$ & $(0.604)$ & $(0.123)$ \\
& -0.00834 & -0.00899 & -0.000931 & -0.000980 & -0.00158 & -0.00304 \\
Income per capita & $(0.307)$ & $(0.354)$ & $(0.659)$ & $(0.636)$ & $(0.668)$ & $(0.470)$ \\
& $(7.00 \mathrm{e}-09)$ & & -0.0133 & & $0.142 * * *$ & $(6.91 \mathrm{e}-06)$ \\
Constant & $-3.565^{* * *}$ & 0.0414 & $0.537 * *$ & $0.428 * * *$ & $-0.627 * *$ & $0.671^{* * *}$ \\
& $(1.81 \mathrm{e}-06)$ & $(0.932)$ & $(0.00371)$ & $(7.22 \mathrm{e}-05)$ & $(0.0498)$ & $(0.00178)$ \\
\hline Observations & 93 & 95 & 93 & 95 & 93 & 95 \\
R-squared & 0.762 & 0.650 & 0.263 & 0.260 & 0.263 & 0.058 \\
\hline \hline
\end{tabular}

pval in parentheses

$* * * p<0.01, * * p<0.05, * p<0.1$

Note: Estimation results from cross section regressions based on country averages over the entire sample period. Infrastructure is measured by the density of the railway network from the WDI, tariffs refer to average applied tariffs retrieved from the WITS database, education refers to secondary school enrollment rate and to share of population with tertiary education in regressions for RCA and share of high-skill products, and income inequality is measured by the net Gini index from the SWIID. 


\section{Appendix V. Panel Vector Autoregressive Model}

Panel VAR analysis has been widely used in empirical studies, especially those looking at underlying dynamic interactions among economic indicators. In general, a p-variate panel VAR of order q with panel-specific fixed effects is represented by the following system of linear equations:

$$
Y_{i t}=Y_{i t-1} A_{1}+Y_{i t-2} A_{2}+\cdots+Y_{i t-p+1} A_{p-1}+Y_{i t-p} A_{p}+u_{i}+e_{i t}
$$

Where $Y_{i t}$ is $(1 \times \mathrm{m})$ vector of dependent variables; $u_{i}$ and $e_{i t}$ are $(1 \times \mathrm{m})$ vectors of individual fixed effects and idiosyncratic errors, respectively. The matrix A contains the parameters to be estimated $\left(A_{1}, A_{2}, \ldots A_{p-1}, A_{p}\right)$.

In this section, we aim to examine the dynamic pattern of macroeconomic and institutional elements and their correlation with the economic complexity index (ECI). In particular, we chose panel VAR as our main approach in order to capture the dynamic inter-dependencies using a minimal set of restrictions, as well as eliminate potential risks of endogeneity due to reverse causality presented in the fixed-effects panel regressions. For instance, if the Gini index and income per capita are included in the panel regression with ECI as the dependent variable, the coefficients may be biased because these variables are mutually affecting each other. The panel VAR approach aims to address these issues. ${ }^{12}$

In order to analyze the short- and medium-term impact of each shock with a clear identification strategy, we use Cholesky decomposition to impose a recursive structure on the VAR. The decomposition is not unique, but depends on the ordering of the variables of interest. ${ }^{3}$ For the analysis of ECI, we choose the following institutional and policy variables: average tariff rate (all products), purchasing power parity per capita (constant international \$), education (secondary school enrollment) and Gini index (net of tax). The ordering of the variables follows the reasoning that policy and institutional variables (etc. tariff rate) should be treated as most exogenous and their changes will tend to have certain contemporaneous effect on non-policy latent variables. For instance, lower tariff rates would reduce inequality in poorer countries as trade liberalization tends to raise wages for unskilled labor if more goods that are intensive in unskilled labor are exported as a result. Income is normally incorporated in the calculation of income inequality, given the likely direct impact. Higher income level can also provide more financial and educational resources, which could potentially increase the rate of school

\footnotetext{
${ }^{1}$ Estimates presented here can be interpreted as the average impact across the sample. In addition, panel VARs have been frequently used to detect average effects across heterogeneous groups of units and to characterize unitspecific divergences relative to the average.

${ }^{2}$ When $\mathrm{T}$ is fixed, a PVAR pooled estimator with dynamic homogeneity, but potentially capturing constant heterogeneities may be biased, and one may want to employ the GMM approach of Arellano and Bond (1991), which is consistent even when T is small, see Canova and Ciccarelli (2013).

${ }^{3}$ Main results are robust to alternative ordering choices.
} 
enrollment and education attainment. However, education investment generally has a delayed impact on income level, since it takes years of experience to transform knowledge obtained in class into higher labor market values. Increasing educational attainment tends to reduce inequality, especially in the bottom half of the earnings distribution. Therefore, based on this argument, we chose the following order as model input (our assumptions imply that right-side variables will not have contemporaneous effect on the left-side variable): tariff rate, income, education, Gini index and ECI.

In addition, we address the model selection by using multiple selection criteria in order to decide the number of lags to be used in the estimation. Specifically, we provide the following statistics according to the three model selection criteria by Andrews and Lu (2001) ${ }^{4}$ :

\begin{tabular}{|c|cccccc|}
\hline lag & CD & J & J pvalue & MBIC & MAIC & MQIC \\
\hline 1 & 0.9999996 & 52.55464 & 0.302053 & -153.3874 & -43.44536 & -87.25916 \\
2 & 0.9999992 & 23.85539 & 0.6891452 & -96.27747 & -32.14461 & -57.70266 \\
3 & 0.9999726 & 12.109 & 0.5975492 & -47.95743 & -15.891 & -28.67002 \\
\hline
\end{tabular}

Based on the overall coefficient of determination, first-order panel VAR is the preferred model, since this has the smallest MBIC, MAIC and MQIC. Based on the selection criteria, we fit a first-order panel VAR model instrumented by 5 lags of all included variables using GMM-style estimation. Impulse response functions (IRFs) from estimation for 21 LAC countries over the period 1995-2012 are presented in Figure 1.5

The result below conveys a mixed picture. There is no significant change in ECI at impact in response to the impulse from income, education and inequality. The impact of tariffs dissipates after one year and gradually moves into negative territory. Income exerts positive impact on complexity, which is in line with our prior about the complexity-income interaction over the medium term. Education, on the other hand, seems to comprise two opposite effects: initially negative, but positive afterwards. Income inequality measured by the Gini index, similar as in the panel regressions, has a negative impact on economic complexity, both in the short and long term.

Results for the other variables are generally in line with our expectation, except for certain pairs where the confidence interval becomes too wide to distinguish the real impact in the long run. Education, for example, has a clear upward path in response to a positive shock in income per capita. While a shock to income inequality seems to negatively affect education, this effect is not significant, given the width of the confidence band that crosses zero.

\footnotetext{
${ }^{4}$ Based on Andrews and Lu (2001). The paper introduces three consistent model and moment selection criteria (MMSC-AIC, MMSC-BIC and MMSC-HQIC) to select the correct model specification and all correct moment condition asymptotically.

${ }^{5}$ The IRF confidence intervals are computed using 200 Monte Carlo draws based on the estimated model.
} 
We acknowledge the limitations to further analyze the relationship between economic complexity and its determinants. In particular, a structure of dynamic interdependencies (unitspecific interaction) could be imposed to further analyze micro impact between each country pair or group effect, as country interconnectedness may result in unique bilateral features.

Moreover, the availability of more observations would facilitate the building of a more robust and comprehensive model.

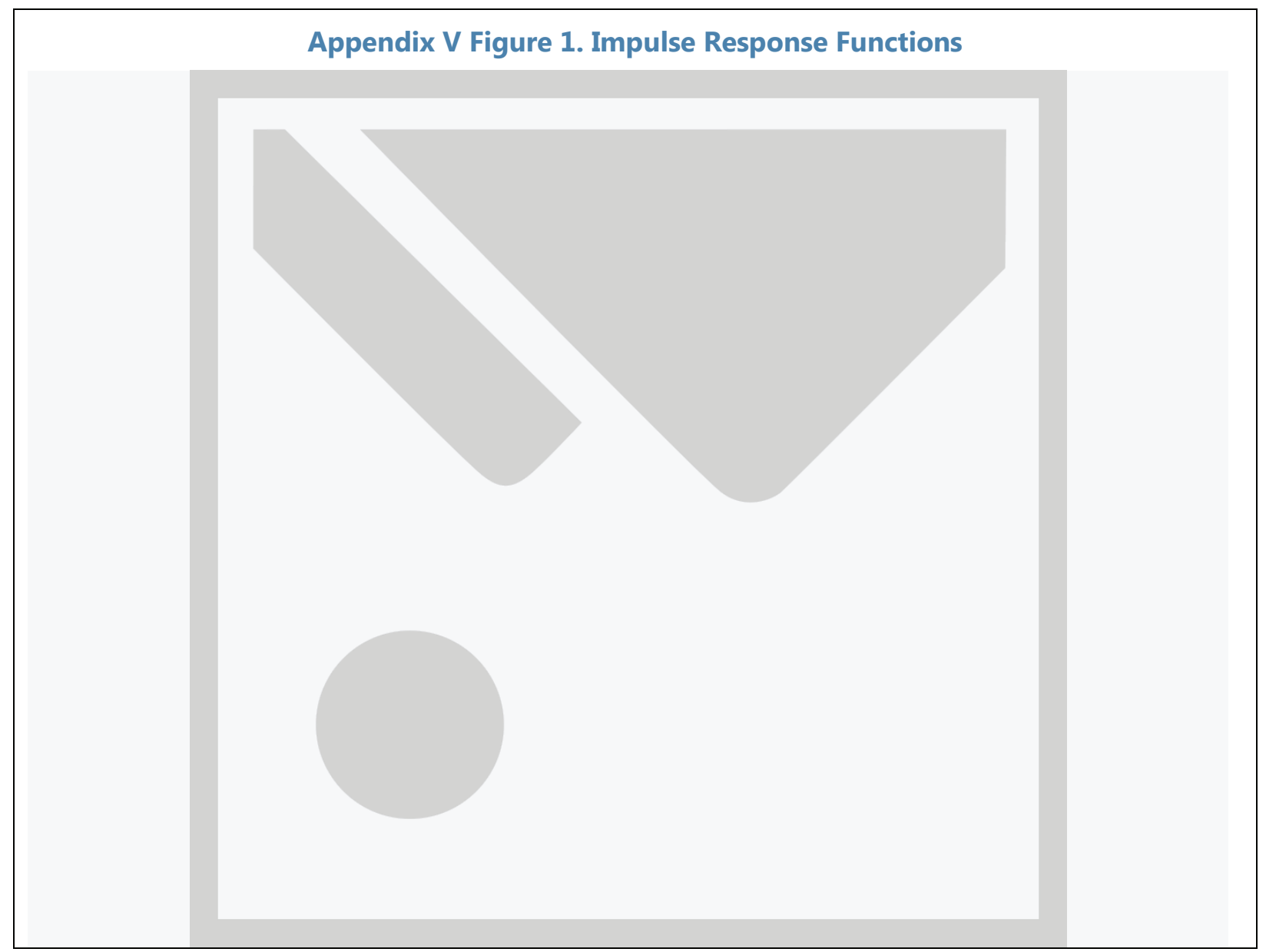

